\title{
Three-dimensional finite element investigation into effects of implant thread design and loading rate on stress distribution in dental implants and anisotropic bone
}

\author{
Dawit Bogale Alemayehu ${ }^{1}$, and Yeau-Ren Jeng 1,2,* \\ ${ }^{1}$ Department of Biomedical Engineering, National Cheng Kung University (NCKU), Tainan 70101, Taiwan \\ ${ }^{2}$ School of Smart Semiconductor and Sustainable Manufacturing, National Cheng Kung University (NCKU), \\ Tainan 70101, Taiwan \\ * Correspondence: imeyrj@gs.ncku.edu.tw; +886933278212.
}

\begin{abstract}
Variations in the implant thread shape and occlusal load behavior may result in significant changes in the biological and mechanical properties of dental implants and surrounding bone tissue. Most previous studies consider a single implant thread design, an isotropic bone structure, and a static occlusal load. However, the effects of different thread designs, bone material properties, and loading conditions are important concerns in clinical practice. Accordingly, the present study performs Finite Element Analysis (FEA) simulations to investigate the static, quasi-static and dynamic response of the implant and implanted bone material under various thread designs and occlusal loading directions (buccal-lingual, mesiodistal and apical). The simulations focus specifically on the von Mises stress, displacement, shear stress, compressive stress and tensile stress within the implant and the surrounding bone. The results show that the thread design and occlusal loading rate have a significant effect on the stress distribution and deformation of the implant and bone structure during clinical applications. Overall, the results provide a useful insight into the design of enhanced dental implants for an improved load transfer efficiency and success rate.
\end{abstract}

Keywords: quasi-static load; abutment screw; dental implant; finite element method; dynamic load; mesiodistal

\section{Introduction}

Dental implants have become increasingly common as a method for replacing missing teeth in recent decades [1-4]. However, while some studies have reported an implant success rate as high as $78-100 \%$ [5], other studies have indicated that single tooth replacement failures may occur for a variety of reasons [6], including implant surface, implant design, and bone quality factors [7] and early bone loss in the dental implant region[8]. Numerous studies have found a link between the success of dental implants, the biological tissue structure of the bone, the mechanical strength of the bone and implant, and the surgical technique employed to insert the implant $[6,9,10]$. In practice, the bio-structure of dental implants is of critical importance in determining the success rate of the implant procedure since it affects the bone directly and causes the stress distribution to change from constant to variable, thereby putting both the implant and the bone at risk of biomechanical overload failure [11]. The success rate of dental implants is also crucially dependent on the efficiency of the stress transfer from the implant to the supporting bone [1214], which depends in turn on many factors, including the loading condition [11], the implant thread design $[2,15,16]$, and the bone material properties [17]. 
The Finite Element Method (FEM) provides an extremely efficient approach for analyzing biomechanical problems [18-21]. FEM is particularly attractive for the analysis of biomechanical processes which are difficult (if not impossible) to examine in vivo or in vitro. As a result, it has been used extensively in the literature to evaluate the stress and deformation behavior of dental implants with a view to improving their success rate $[3,3,14,22-33]$. The study by Mosavar et al. was inspired by a paucity of numerical models of bone-implant interactions for diverse osseointegration and the simplification of bone as an isotropic material in prior investigations. Further, four different thread form implants were modeled and subjected to static occlusal load and varied osseointegration conditions of the bone-implant interface using finite element analysis. It is found that the cervical cortical bone region received the most stress, as did the first thread [34]. And Amaral et al. studied single implant failure in the anterior region than a 2-implant-retained mandibular overdenture because of high stress concentration around this prosthesis. Two 3-D finite element models of mandibular overdentures are supported by a single implant and subjected to a static oblique force applied to the incisal edge of the central mandibular incisors. It is reported that the attachment, implant and bone, in both models showed equal stress levels [35]. Another research by Aslam et al., using 3D nonlinear FEA, determined the impact of platform switching on stress distribution in dental implants and periimplant bone. And to replicate occlusal loads, each model was subjected to axial and nonaxial static forces. Finally, it is reported that switching platforms reduced peri-implant bone stress, which may assist prevent marginal bone resorption [24].

During their service lives, dental implants are subjected to both static and dynamic loads [36]. However, most previous studies only consider the effects of static loads applied to a single point on the implant surface[24,35,37,38]. As a result, the induced stress does not usually exceed the yield strength of the dental implant material (e.g., $550 \mathrm{MPa}$ for titanium, [39]) or bone (190 MPa for cortical bone, and $10 \mathrm{MPa}$ for cancellous bone [39]). However, Gotfredsen et al. [40-42] showed that in practical implant situations, high dynamic loads are much more destructive than static loads, and therefore have a critical effect on the implant success rate. The results showed that dynamic loading produced a higher maximum stress than static loading and had a greater effect on the stress range as the elastic modulus varied. Mosovar et al. [34] examined the effects of four different thread shapes on the stress distribution in anisotropic bone under static loading conditions, and found that a square thread resulted in an improved performance. Bulaqi et al. [39] showed that for short dental implants subject to dynamic loads, a greater crown height space (CHS) contributed to screw loosening and fatigue fracture. Kayabaşi et al. [43] showed that for dental implants with a buttress thread shape, dynamic loading increased the stress within the implant by as much as 10-20\%. Gehrke et al. [44] investigated one-piece and two-piece sintered dental implants subjected to quasi-static loading at a 30 degrees angle to the implant axis. The results showed that both implants could resist the loads produced during mastication. Lofaj et al. [45] conducted a numerical and experimental investigation into the stress distributions in mono- and bicortical dental implants under three-axial loading. It was found that bicortical fixation resulted in a lower compression stress than monocortical fixation for fresh implants. However, the performance advantage of the bicortical fixation method reduced over time because of osseointegration.

The shape of the implant thread has a significant effect on both the stress distribution within the implant and the marginal bone rehabilitation [12]. Accordingly, an appropriate design of the thread pattern is essential to improve the uniformity of the stress distribution and reduce the stress intensity at the bone-implant interface (BII) $[15,46]$. In clinical practice, the level and strength of the osseointegration effect are both strongly related to the type of force generated at the BII. In particular, tensile and shear forces tend to inhibit osseointegration, whereas compressive forces promote healing between the implant and surrounding bone $[15,47,48]$. Many thread designs are available for dental implants, including square, triangular, buttress, reverse buttress, and trapezoidal. The thread design and associated parameters (e.g., face angle, thread width, thread pitch, and so on) have a critical effect on both the type of force produced at the BII (i.e., tensile, compressive, or 
shear) and the efficiency with which the load is transferred to the bone [34,48]. For example, triangular threads generate a higher shear force, while square-shaped threads produce a lower shear force and higher compressive force [46]. For square and buttress threads, the axial load is dissipated mainly through compressive forces $[34,49,50]$. However, for triangular and reverse buttress threads, the load is transferred through a combination of shear forces, compressive forces, and tensile forces [48]. Among the various thread designs, the square design reduces the maximum von Mises stress [9]. Albrektsson et al. [51] showed that the stress concentration of dental implants can be further reduced by curving the tops of the threads. Hansson and Werke [46] similarly showed that the maximum stress induced in the bone, and the ability of the implant to bear the load depends not only on the thread design (e.g., triangular, square, buttress, and so on), but also on the detailed parameters of the thread design, including the pitch, thread width and face angle.

The bone material property also has an important effect on the stress distribution in dental implant systems. However, the accurate modeling of bone-related organs using finite element modeling (FEM) methods is challenging due to their inherent inhomogeneous and anisotropic characteristics[1,4,34,52]. As a result, almost all previous studies consider the implanted bone to be isotropic, homogeneous, and linearly elastic $[3,4,25,37,53-$ 57]. However, such a simplification results in significantly lower stress predictions for the peri-implant bone than those observed in practice [8]. Consequently, the usefulness of the simulation results for practical clinical purposes is greatly impaired.

The present study performs a comprehensive FEM investigation into the effects of five different dental implant thread designs (square, buttress, reverse buttress, trapezoidal, and triangular) on the stress distribution induced within the implant and surrounding bone under three different loading rates, namely static, quasi-static and dynamic. The simulations consider the implant to consist of four components, i.e., the crown, abutment, screw, and implant. Moreover, the implanted bone is modeled as an anisotropic structure consisting of a spongy bone interior and a compact bone exterior. Finally, the simulations consider the implant to be jointly loaded by three external forces acting in the mesiodistal, buccal-lingual and apical directions, respectively. The simulations focus specifically on the von Mises stress, displacement magnitude, shear stress, compressive stress, and tensile stress under each of the considered thread designs and loading conditions. The results are expected to be of significant benefit in the design of dental implants with an improved success rate under realistic clinical conditions.

\section{Materials and Methods}

\subsection{Implant and Bone Models}

As described above, the simulations considered five basic thread designs, namely square, buttress, reverse buttress, trapezoidal and triangular. For both buttress designs, two different flank profiles were implemented, namely straight flank (SF) and curved flank (CF). Thus, as shown in Fig. 1, a total of seven three-dimensional (3D) implant models were constructed, (note that for clarity of presentation, only the first thread in each model is shown.) For each model, the implant length, diameter, and pitch were specified as $14 \mathrm{~mm}, 4.1 \mathrm{~mm}$ and $0.8 \mathrm{~mm}$, respectively, in accordance with the design specification of the commercial Straumann ${ }^{\circledR}$ Standard Plus (SP) dental implant (Straumann, Basel, Switzerland). As shown in Fig. 2, the prosthetic was assumed to consist of four components, namely the crown, abutment, screw, and implant. Furthermore, each implant was embedded in anisotropic bone consisting of a spongy bone interior (cancellous bone) and a compact bone exterior (cortical bone). 


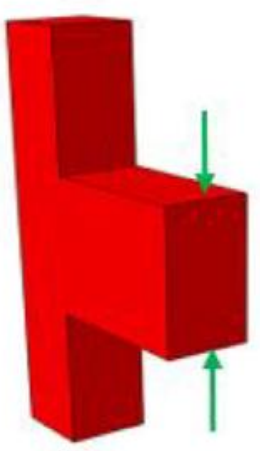

(a)

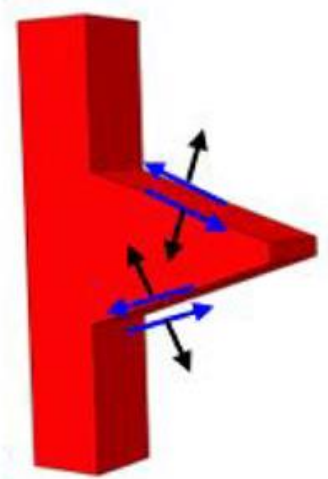

(d)

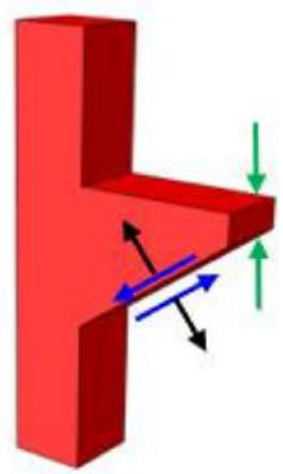

(b)

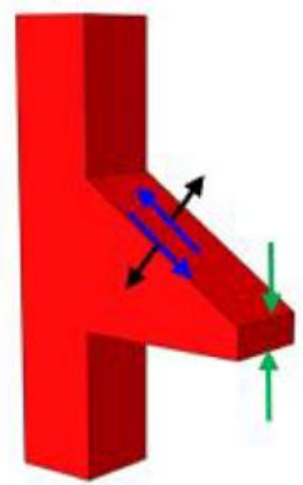

(e)

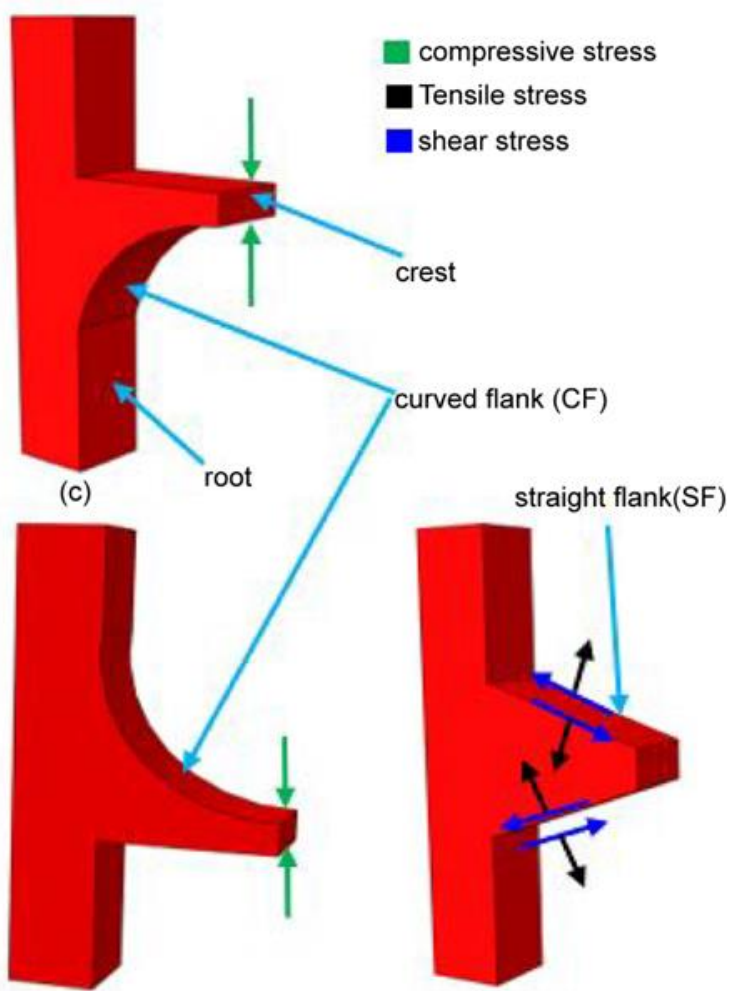

(g)

Figure 1. Thread design models and directions of transferred loads, (a) Square, (b) buttress (SF), (c) buttress (CF), (d) trapezoidal, (e) reverse buttress (SF), (f) reverse buttress $(\mathrm{CF})$, and $(\mathrm{g})$ triangular.

As described in Section 2.3, the implants were assumed to be subjected to a combined load acting jointly in the mesiodistal, buccal-lingual and apical directions, respectively. Moreover, the load was applied under three different rates, namely static, quasi-static and dynamic. The resulting shear stress, tensile stress and compressive within the implant were analyzed by means of finite element simulations performed in ABAQUS. 

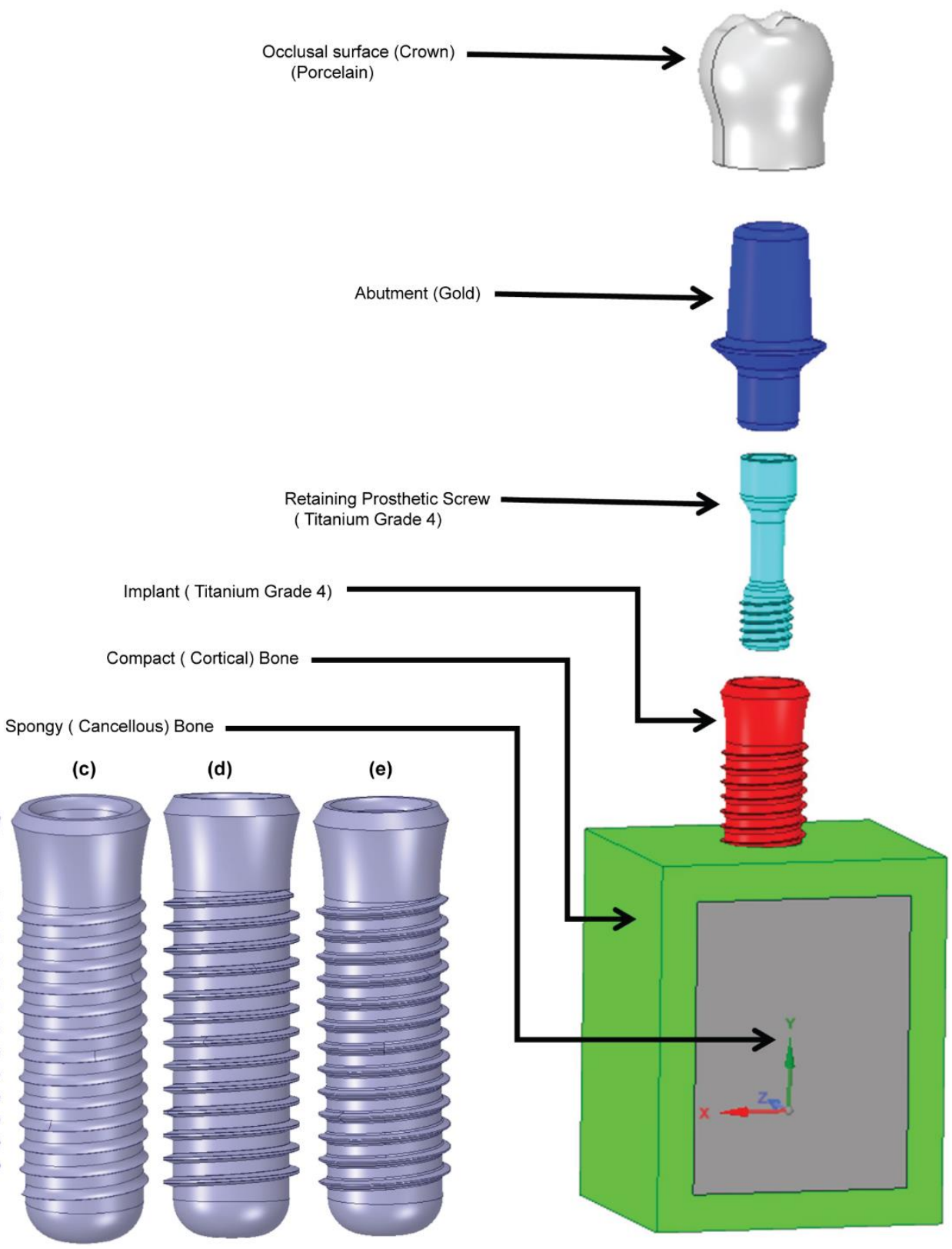

Figure 2. 3D models of implants and bone: a) square, b) buttress, c) reverse buttress, d) trapezoidal, and e) triangular.

\subsection{Material Properties and Mesh}

The static and quasi-static responses of the dental implants were investigated by means of ABAQUS Standard simulations, while the dynamic response was investigated using ABAQUS Explicit. The implants and bone models were discretized using a free meshing technique with C3D10M 10-node modified quadratic tetrahedron elements. As shown in Fig. 3 the models were meshed using a $0.2-\mathrm{mm}$ element size in regions of the computational domain with a high stress concentration, and $0.35-\mathrm{mm}$ or 2-mm size elements elsewhere. Table 1 presents the mesh statistics of the five basic implant models. The mechanical properties of the implant and bone materials are shown in Table 2. It is 


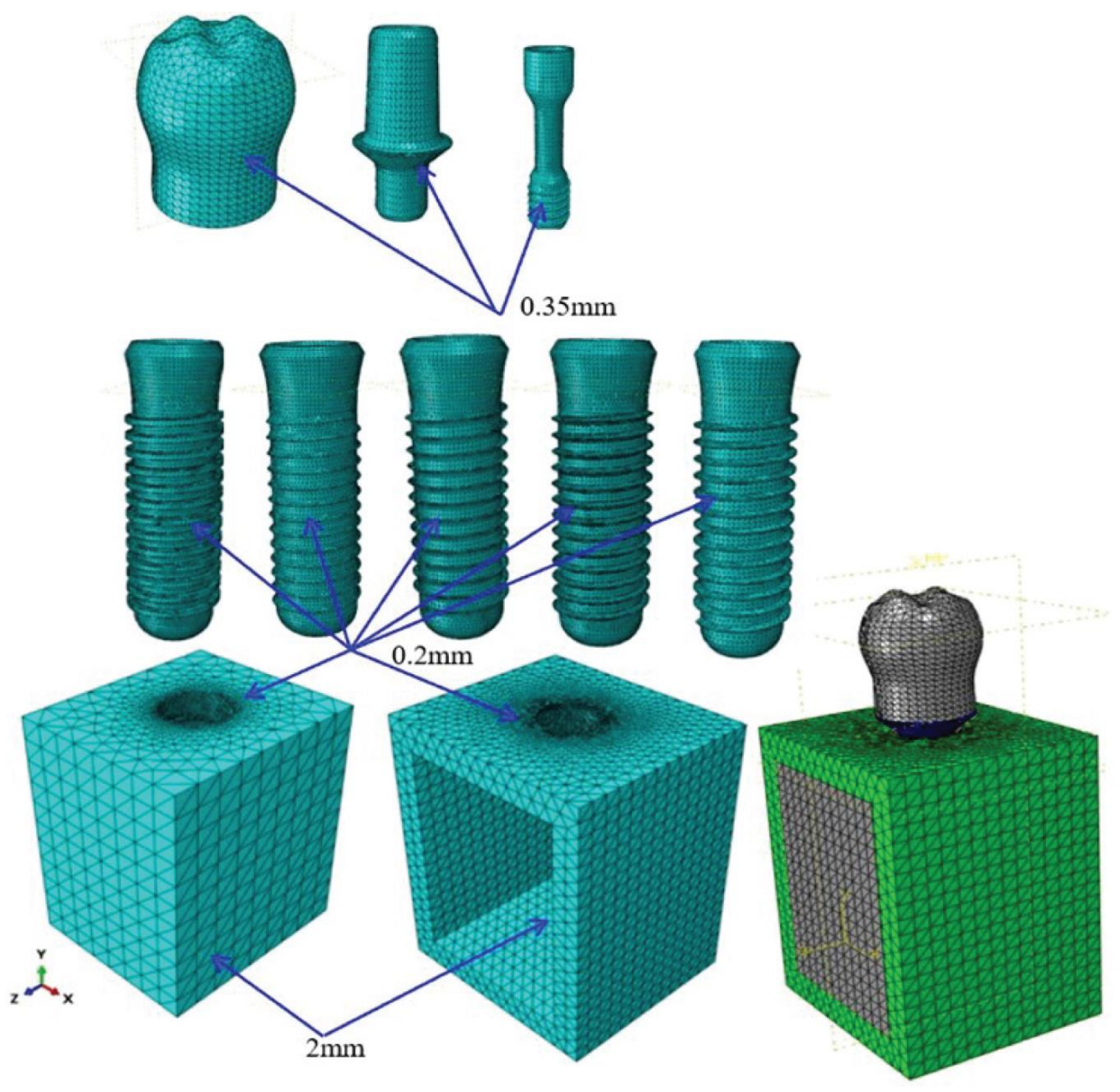

Figure 3. Computational meshes for implant and bone models.

noted that the mechanical properties of the crown, abutment, screw, and implant component are all assumed to be elastic, isotropic, and homogenous.

Table 1. Mesh statistics of different implant and bone model 


\begin{tabular}{|c|c|c|c|c|c|c|c|c|c|c|c|c|c|c|}
\hline \multirow[b]{2}{*}{ Thread Shape } & \multicolumn{2}{|c|}{ Crown } & \multicolumn{2}{|c|}{ Abutment } & \multicolumn{2}{|c|}{ Screw } & \multicolumn{2}{|c|}{ Implant } & \multicolumn{2}{|c|}{ Cortical Bone } & \multicolumn{2}{|c|}{ Trabecualr Bone } & \multicolumn{2}{|c|}{ Total } \\
\hline & No.Element & No.Node & No.Element & No.Node & No.Element & No.Node & No.Element & No.Node & No.Element & No.Node & No.Element & No.Node & No.Element & No.Node \\
\hline reverse Buttress (CF) & 28366 & 6087 & 21417 & 5081 & 16901 & 3724 & 168760 & 38512 & 40743 & 8972 & 306173 & 57166 & 582360 & 119542 \\
\hline buttress (CF) & 36970 & 7809 & 20725 & 4969 & 17022 & 3748 & 161164 & 37266 & 41045 & 9020 & 334731 & 64236 & 611657 & 127048 \\
\hline Square & 26370 & 5698 & 21115 & 5033 & 16894 & 3729 & 235374 & 47451 & 49741 & 10912 & 343846 & 68114 & 693340 & 140937 \\
\hline triangular & 28060 & 6023 & 21455 & 5097 & 16876 & 3729 & 235860 & 50594 & 40217 & 8873 & 373046 & 70342 & 715514 & 144658 \\
\hline trapezoidal & 27979 & 5990 & 20991 & 5014 & 16937 & 3736 & 168399 & 35006 & 49974 & 10946 & 380451 & 72147 & 664731 & 132839 \\
\hline
\end{tabular}


Table 2. Physical properties of materials for the FEA [39, 59]

\begin{tabular}{|c|c|c|c|c|c|c|}
\hline \multirow[t]{2}{*}{ Materials } & \multicolumn{2}{|c|}{$\begin{array}{l}\text { Young's modulus E } \\
\text { (MPa) }\end{array}$} & \multicolumn{2}{|c|}{ Poisson's ratio v } & \multirow[t]{2}{*}{ density (g/cm3) } & \multirow[t]{2}{*}{ Strength (MPa) } \\
\hline & Ex & 12600 & vxy & 0.3 & & \\
\hline \multirow{5}{*}{ Cortical bone } & Ey & 12600 & vyz & 0.253 & \multirow{5}{*}{3} & \multirow{5}{*}{190} \\
\hline & $\mathrm{Ez}$ & 19400 & $v x z$ & 0.253 & & \\
\hline & & & vyx & 0.3 & & \\
\hline & & & vzy & 0.39 & & \\
\hline & & & $v z x$ & 0.39 & & \\
\hline \multirow{6}{*}{ Cancellous bone } & Ex & 1148 & vxy & 0.055 & \multirow{6}{*}{3} & \multirow{6}{*}{10} \\
\hline & Ey & 210 & vyz & 0.01 & & \\
\hline & $\mathrm{Ez}$ & 1148 & $v x z$ & 0.322 & & \\
\hline & & & vyx & 0.01 & & \\
\hline & & & vzy & 0.055 & & \\
\hline & & & $v z x$ & 0.322 & & \\
\hline Gold abutment* & \multicolumn{2}{|c|}{136000} & \multicolumn{2}{|c|}{0.37} & 17.5 & 765 \\
\hline Porcelain & \multicolumn{2}{|c|}{68900} & \multicolumn{2}{|c|}{0.28} & 2.44 & 145 \\
\hline Titanium grade $4 *$ & \multicolumn{2}{|c|}{110000} & \multicolumn{2}{|c|}{0.34} & 4.5 & 550 \\
\hline
\end{tabular}

\subsection{Load and Boundary Conditions}

As shown in Fig. 4(a), the occlusal surface of the dental implant was subjected to a combined loading condition in the mesiodistal, buccal-lingual and apical directions. In performing the simulations, the magnitudes of the loads in the three directions were set as $23.4 \mathrm{~N}, 17.1 \mathrm{~N}$ and $114.6 \mathrm{~N}$, respectively, and were applied to a dummy reference point located at a distance of $3 \mathrm{~mm}$ from the occlusal surface using a multi-point constraint (MPC) technique. The resulting equivalent load was equal to $118.2 \mathrm{~N}$ at an angle of 75.8 degrees to the occlusal plane [39,43,58,59]. As described in the previous section, the simulations considered three different loading rates, namely static, quasi-static and dynamic. In the latter case, the external load was applied for 0.5 seconds to replicate the natural mastication cycle, which typically has a frequency of $2 \mathrm{~Hz}[39,60]$. Figures 4(b)-4(f) present cross-sectional views of the five basic thread designs considered in the present study. In performing the simulations, a zero-displacement boundary condition was initially applied at the interface between the implant and mandible bone in the $\mathrm{X}$-, $\mathrm{Y}$ and Z-directions. Moreover, to mimic the actual clinical situation at the interface between the implant and bone, frictional contact interfaces were implemented with values of 0.65 between the implant and cortical bone, and 0.77 between the implant and cancellous bone [61]. 


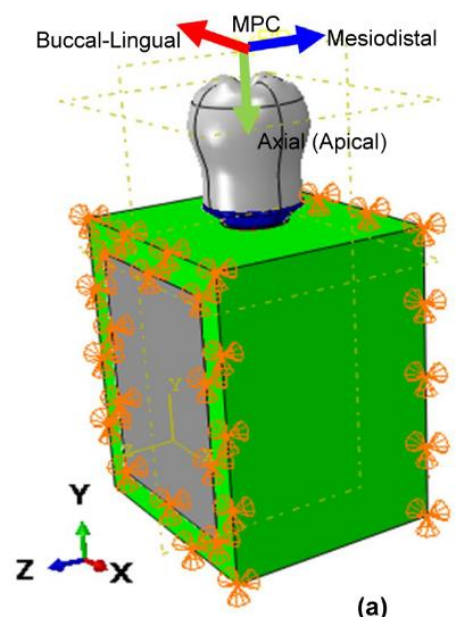

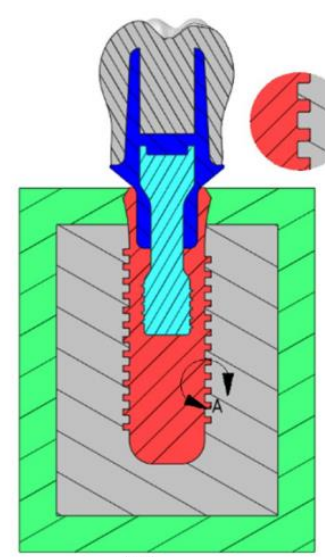

(b)

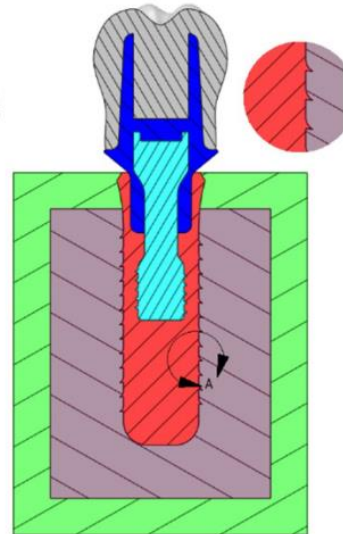

(c)

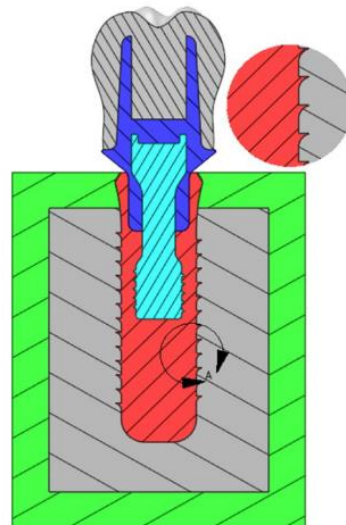

(d)

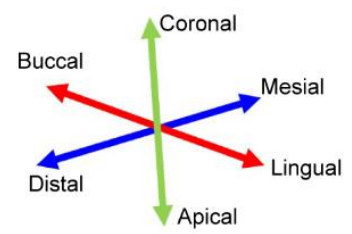

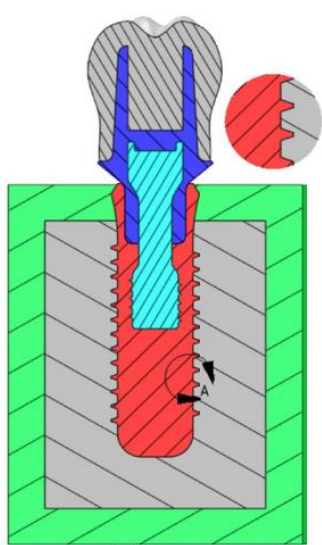

(e)

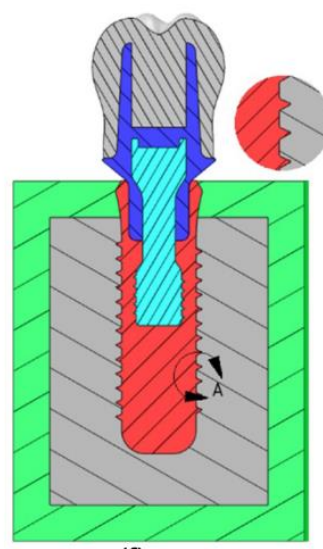

(f)

Figure 4. a) Loading and boundary conditions. Sectional views of: $b$ ) square thread, c) buttress thread, d) reverse buttress thread, e) trapezoidal thread, and f) triangular thread.

\section{Results}

In performing FEA simulations, convergence tests are required to achieve an adequate tradeoff between the computational cost of the simulation process and the accuracy of the numerical solutions. Accordingly, the five implant models were implemented with eight different element sizes in the range of $0.05 \sim 0.4 \mathrm{~mm}$. For each mesh size, the maximum von Mises stress was computed in the compact bone region. The simulation results were then inspected to determine the mesh size at which the change in the maximum von Mises stress was limited to less than $5 \%$. And the convergence test was performed under dynamic loading rate. The corresponding results are presented in Fig. 5. A detailed inspection shows that the maximum von Mises stress increases by just $3.96 \%, 4.44 \%, 3.10 \%, 4.00 \%$ and $1.26 \%$ as the element size increases from 0.2 to $0.25 \mathrm{~mm}$ in the square, buttress, reverse buttress, trapezoidal, and triangular models, respectively. Accordingly, an element size of $0.2 \mathrm{~mm}$ 
was adopted as the optimal seed size for the meshing process (see Fig. 3).

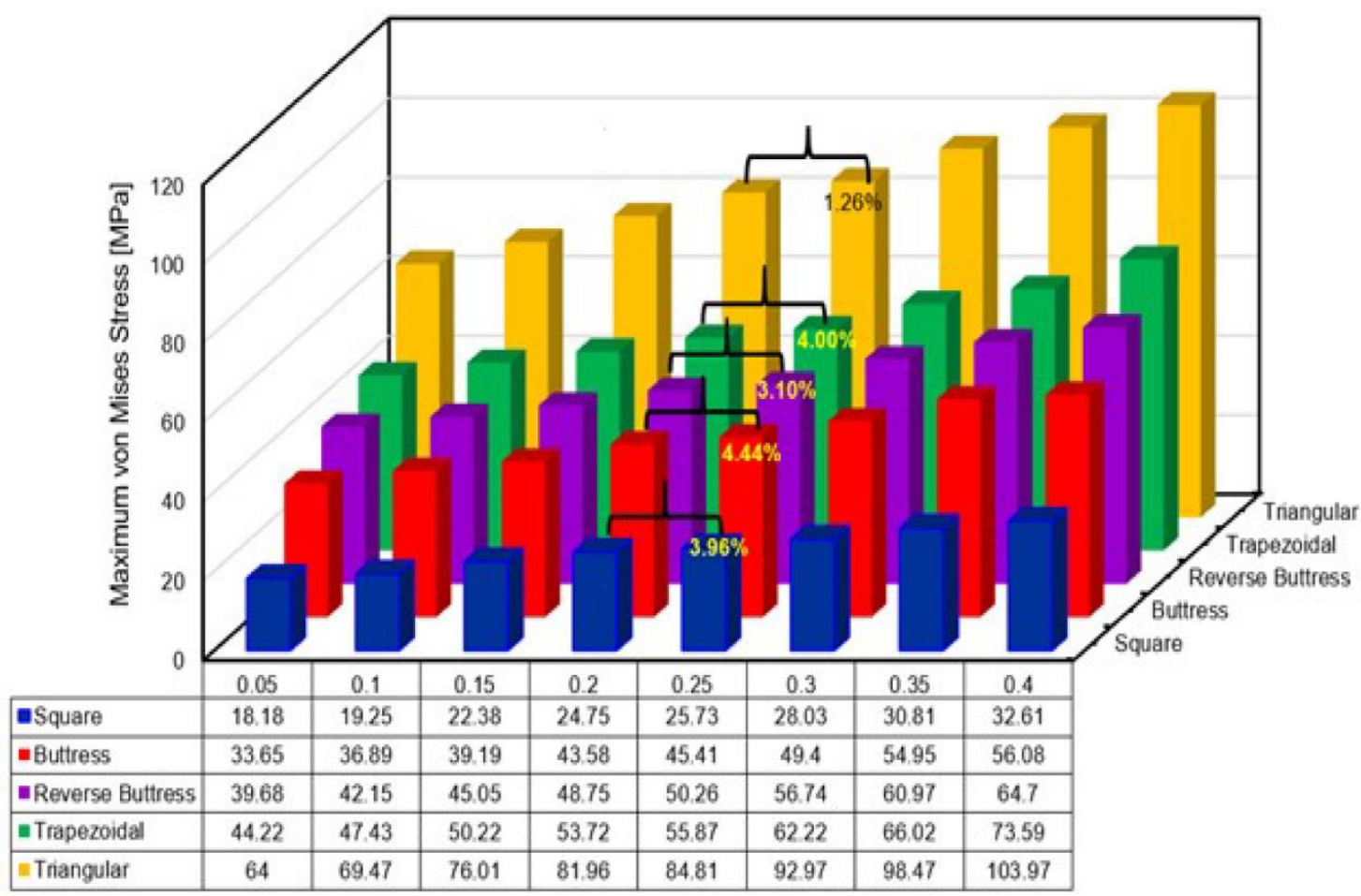

Figure 5. Maximum von Mises stress for different implant models and element sizes.

Figure 6 shows the variation of the load applied to the occlusal surface of the crown in the mesiodistal, buccal-lingual and apical directions over the course of the mastication cycle $(0.5 \mathrm{~s})$. Figure 7 shows the corresponding variation in the maximum von Mises stress in the crown, abutment, abutment screw, Buttress thread implant, cortical bone, and spongy bone regions of the model, respectively. It is seen that for all of the implant components, the maximum von Mises stress is produced under buccal-lingual loading, followed by mesiodistal and axial loading, respectively. Moreover, the maximum von Mises stress is induced in the implant component of the prosthetic (Fig. 7(d)). The maximum stress has a value of $278.63 \mathrm{MPa}$ and is thus around $50.66 \%$ of the implant material (titanium) yield strength (see Table 1). By contrast, the minimum von Mises stress is produced in the crown region of the implant (Fig. 7(a)). Observing the results presented in Fig.7(e) for the cortical bone region of the model, it is seen that the maximum von Mises stress is produced under axial loading, followed by mesiodistal and buccal-lingual loading, respectively. By contrast, for the spongy bone region of the model, the maximum stress is produced under axial loading, followed by buccallingual and mesiodistal loading (Fig. 7(f)). Comparing the two figures, the maximum von Mises stress in the cortical bone region $(47.21 \mathrm{MPa}$, $22.31 \%$ of the yield strength, see Table 1 ) is higher than that in the 
spongy bone region (11.05 $\mathrm{MPa}, 110 \%$ of the yield strength). Moreover, the maximum von Mises stress is distributed relatively uniformly between the three loading conditions. However, the magnitude of the maximum von Mises stress is significantly reduced and less evenly distributed in the spongy bone region (11.05 MPa under axial loading and 3.06 MPa under mesiodistal loading). In the case of trabecular bone, its yield strength threshold is exceeded under dynamic stress in the axial direction. This increase indicates that trabecular tissue yield strength is higher in compression than in tension. This could result in bone resorption and mineral redistribution to help with bone remodeling. Due to higher stress carrying in the implant, followed by cortical bone, the Von Mises stress is lower in spongy bone for all loading rates.

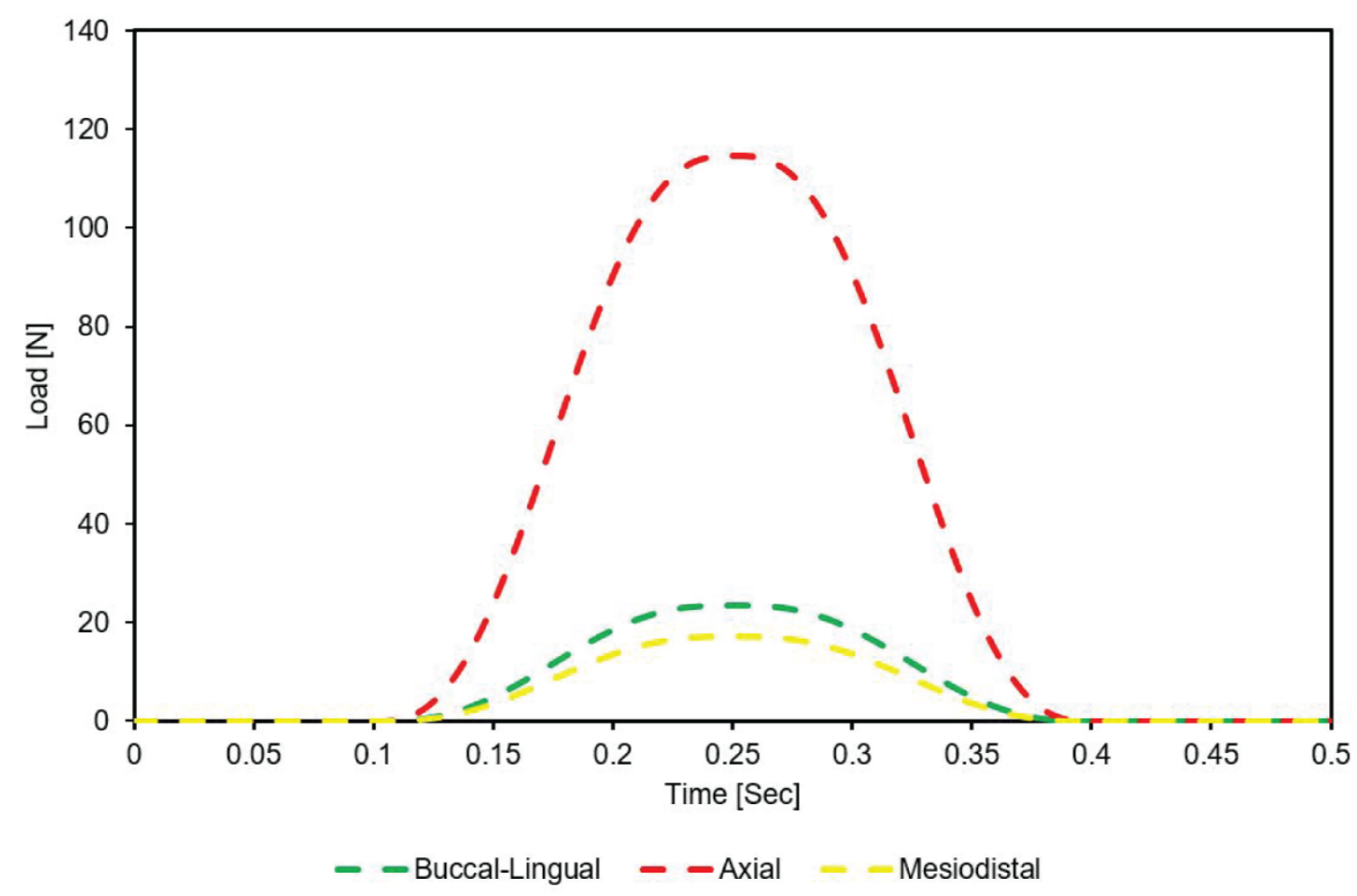

Figure 6. Dynamic loading of crown occlusal surface in buccal-lingual, axial and mesiodistal directions during mastication cycle $(2 \mathrm{~Hz})$. 
(a)

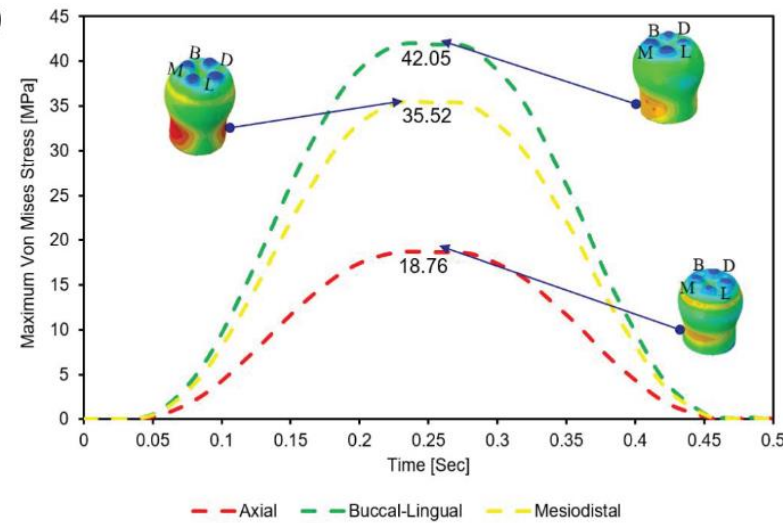

(c)

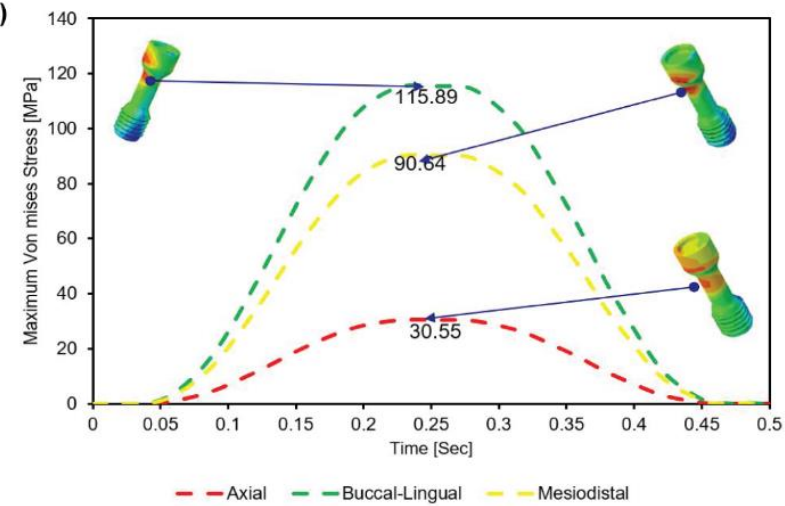

(e)

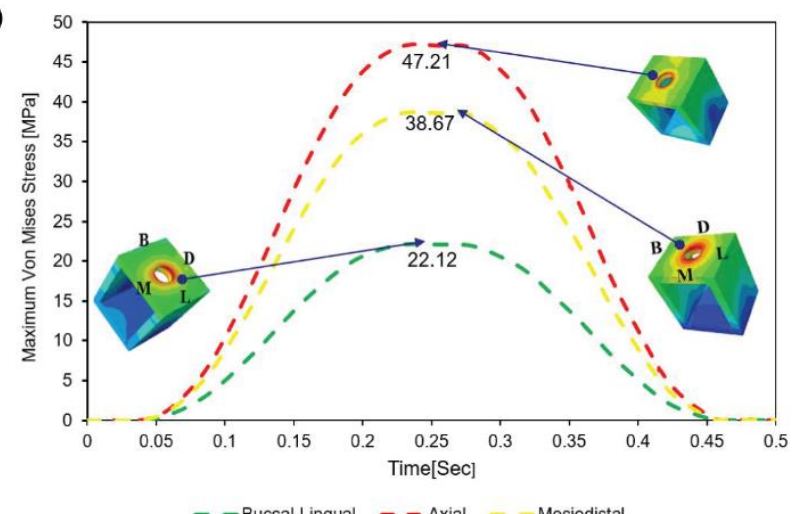

(b)
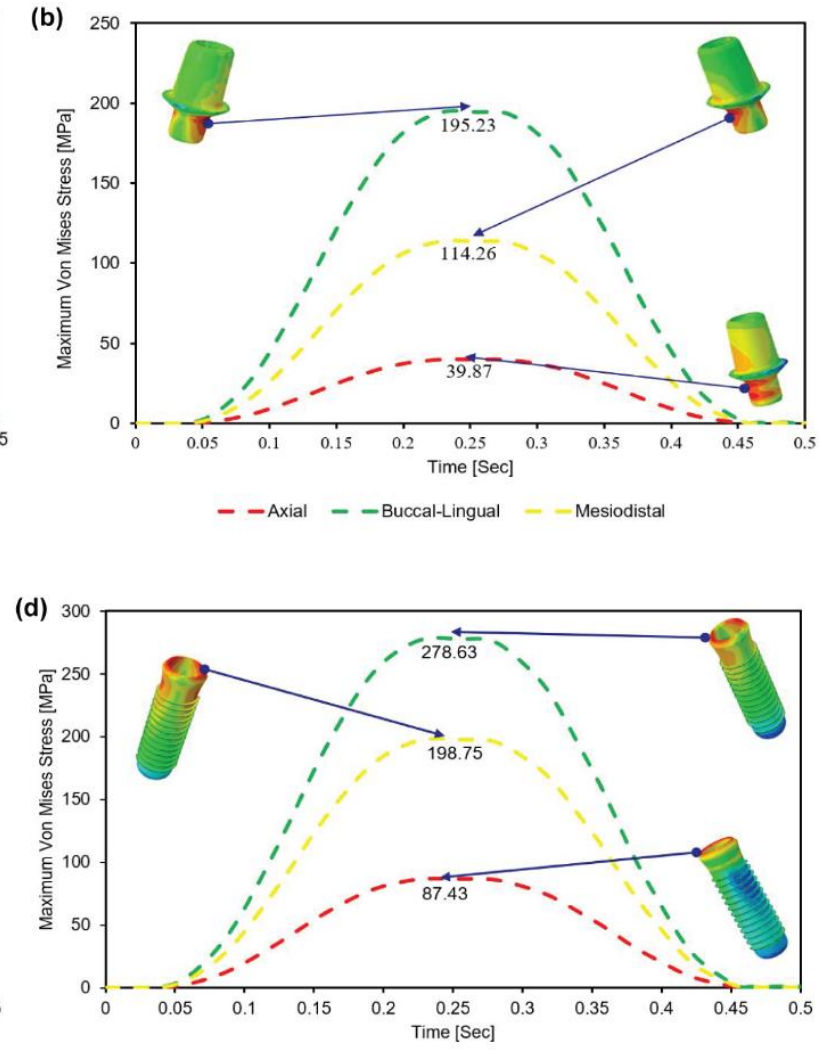

-- Axial -- Buccal-Lingual -- Mesiodistal

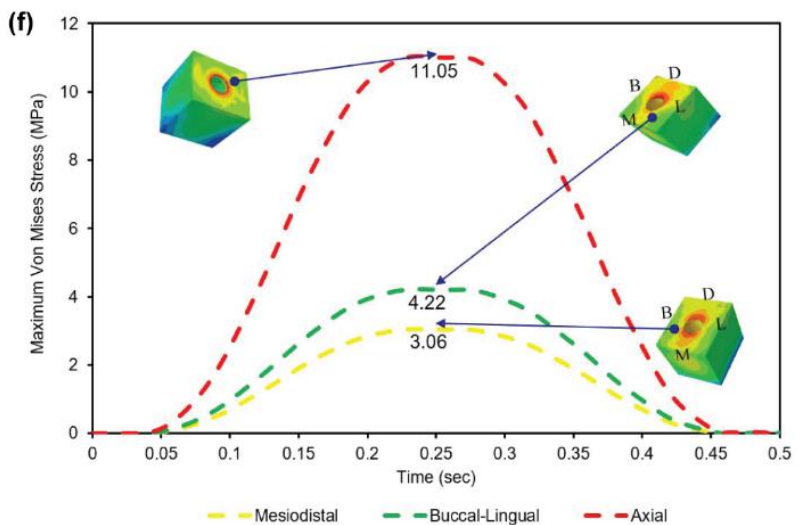

Figure 7. Dynamic loading of crown occlusal surface in buccal-lingual, axial and mesiodistal directions during mastication cycle $(2 \mathrm{~Hz})$.

Table 3 shows the maximum shear stress in the crown, abutment, screw, implant, cortical bone, and spongy bone regions of the five basic thread models for each of the three planes (XY, XZ and YZ) and loading rate conditions (static, quasi-static and dynamic). For each model, the maximum shear stress increases significantly on all planes under the application of a dynamic load (40-99\%). The maximum shear stresses in the three planes (XY, XZ and $\mathrm{YZ}$ ) for the square thread implant in static and dynamic loading were (27.75 MPa, 19.69 MPa, and 17.13 MPa) and (41.66 $\mathrm{MPa}, 29.30 \mathrm{MPa}$, and 25.51 MPa), respectively. The percentage change in maximum shear stress in three planes $(X Y, X Z$, and $Y Z)$ of the dynamic loading rate is shown here $(50.13 \%, 48.81 \%$, and $48.92 \%)$. Similarly, in triangular thread implant the percentage change in the 
maximum shear stress in the three planes ( $X Y, X Z$ and $Y Z)$ of the static and dynamic loading rate is $(95.56 \%, 85.67 \%$, and $99.14 \%)$. However, no significant difference is noted in the stress responses of the various components within each model under a static load and quasi-static load, respectively. Among the five models, the square thread model and buttress thread model yield lower shear stress values than the reverse buttress, trapezoidal and triangular models. Moreover, for all thread models and loading directions, the shear stress in the cortical bone is greater than that in the spongy bone. And the effect of dynamic load on shear stress was significant but varied in every three planes $(X Y, X Z$, and $Y Z$ planes).

Table 2. Maximum shear stress in three different planes of basic thread models under static, quasi-static and dynamic loading conditions.

\begin{tabular}{|c|c|c|c|c|c|c|c|c|c|c|}
\hline \multicolumn{11}{|c|}{ Shear Stress [MPa] for Oblique Load-118.2N } \\
\hline \multirow[b]{2}{*}{ thread type } & \multirow[b]{2}{*}{ components } & \multicolumn{3}{|c|}{ Static load } & \multicolumn{3}{|c|}{ Quasi-Static load } & \multicolumn{3}{|c|}{ Dynamic load } \\
\hline & & $\mathrm{XY}$ & $\mathrm{XZ}$ & $\mathrm{YZ}$ & $\mathrm{XY}$ & $\mathrm{XZ}$ & $\mathrm{YZ}$ & $\mathrm{XY}$ & $\mathrm{XZ}$ & $\mathrm{YZ}$ \\
\hline \multirow{6}{*}{ Square } & CROWN & 7.15 & 13.15 & 5.91 & 7.51 & 13.61 & 6.04 & 10.69 & 19.32 & 8.67 \\
\hline & ABUTMENT & 29.07 & 10.09 & 33.88 & 31.83 & 10.66 & 34.31 & 40.67 & 13.91 & 47.88 \\
\hline & SCREW & 7.44 & 5.18 & 13.24 & 8.00 & 5.41 & 13.93 & 10.06 & 7.62 & 18.38 \\
\hline & IMPLANT & 27.75 & 19.69 & 17.13 & 29.32 & 20.99 & 18.59 & 41.66 & 29.30 & 25.51 \\
\hline & CORTICAL BONE & 4.94 & 8.97 & 3.36 & 5.27 & 9.18 & 3.53 & 7.24 & 13.36 & 5.28 \\
\hline & SPONGY BONE & 1.01 & 1.08 & 1.06 & 1.01 & 1.14 & 1.10 & 1.61 & 2.16 & 1.99 \\
\hline \multirow{6}{*}{ Buttress (CF) } & CROWN & 4.55 & 3.78 & 7.52 & 4.92 & 4.03 & 7.62 & 6.51 & 5.68 & 11.45 \\
\hline & ABUTMENT & 25.00 & 9.63 & 54.53 & 26.66 & 10.17 & 57.38 & 35.10 & 14.46 & 79.61 \\
\hline & SCREW & 9.35 & 10.18 & 15.95 & 9.94 & 10.74 & 17.31 & 14.13 & 14.71 & 23.66 \\
\hline & IMPLANT & 35.90 & 22.55 & 14.98 & 38.45 & 23.28 & 15.72 & 53.38 & 33.92 & 26.80 \\
\hline & CORTICAL BONE & 5.71 & 10.73 & 2.40 & 5.73 & 11.22 & 2.49 & 9.69 & 16.32 & 7.21 \\
\hline & SPONGY BONE & 0.53 & 0.66 & 0.64 & 0.56 & 0.69 & 0.65 & 0.99 & 1.26 & 2.46 \\
\hline \multirow{6}{*}{$\begin{array}{l}\text { Reverse Buttress } \\
\text { (CF) }\end{array}$} & CROWN & 14.26 & 6.72 & 36.69 & 15.31 & 7.21 & 39.45 & 20.68 & 9.94 & 53.29 \\
\hline & ABUTMENT & 46.29 & 46.20 & 53.10 & 49.62 & 49.46 & 56.95 & 72.01 & 73.94 & 82.65 \\
\hline & SCREW & 14.81 & 10.37 & 19.19 & 16.04 & 11.32 & 20.84 & 22.12 & 15.80 & 28.72 \\
\hline & IMPLANT & 43.27 & 32.08 & 19.24 & 43.57 & 32.34 & 19.39 & 77.41 & 58.48 & 34.45 \\
\hline & CORTICAL BONE & 6.72 & 12.19 & 2.76 & 7.15 & 13.08 & 2.93 & 12.73 & 24.28 & 8.26 \\
\hline & SPONGY BONE & 0.63 & 0.90 & 0.58 & 0.69 & 0.99 & 0.63 & 2.26 & 3.39 & 2.12 \\
\hline \multirow{6}{*}{ Trapezoidal } & CROWN & 5.17 & 3.85 & 11.40 & 5.58 & 4.11 & 12.11 & 7.76 & 6.22 & 18.81 \\
\hline & ABUTMENT & 26.77 & 15.72 & 55.36 & 28.93 & 17.05 & 59.36 & 41.02 & 24.37 & 84.76 \\
\hline & SCREW & 9.83 & 5.26 & 17.11 & 9.89 & 5.36 & 17.25 & 17.66 & 9.47 & 32.56 \\
\hline & IMPLANT & 51.59 & 26.71 & 20.61 & 53.89 & 28.07 & 22.03 & 80.55 & 46.23 & 34.09 \\
\hline & CORTICAL BONE & 6.94 & 11.81 & 2.98 & 7.56 & 12.93 & 3.25 & 13.18 & 23.02 & 5.65 \\
\hline & SPONGY BONE & 0.61 & 0.68 & 0.68 & 0.65 & 0.73 & 0.74 & 2.52 & 2.81 & 2.89 \\
\hline \multirow{2}{*}{ Triangular } & CROWN & 4.98 & 3.30 & 6.84 & 5.41 & 3.60 & 7.39 & 8.12 & 5.78 & 12.02 \\
\hline & ABUTMENT & 27.79 & 8.55 & 60.12 & 28.04 & 8.63 & 60.64 & 53.42 & 15.90 & 119.62 \\
\hline
\end{tabular}




\begin{tabular}{lcccccccccc}
\hline SCREW & 10.17 & 16.83 & 16.72 & 10.73 & 17.87 & 17.97 & 16.73 & 29.08 & 30.50 \\
& IMPLANT & 36.69 & 33.07 & 17.47 & 39.82 & 35.80 & 19.04 & 71.75 & 61.40 & 34.79 \\
CORTICAL BONE & 8.23 & 12.23 & 3.26 & 8.77 & 13.09 & 3.57 & 27.32 & 46.43 & 14.44 \\
SPONGY BONE & 0.79 & 0.92 & 0.55 & 0.86 & 1.00 & 0.61 & 2.81 & 3.58 & 2.75 \\
\hline
\end{tabular}

Figures $8(\mathrm{a}-\mathrm{c})$ show the maximum displacements of the crown, abutment, screw, implant, cortical bone and spongy bone regions of the five models under static, quasi-static and dynamic loading conditions, respectively. For all the thread models, and each of the three loading conditions, the maximum displacement occurs in the crown region of the prosthetic, while the minimum displacement occurs in the spongy bone. Furthermore, for each loading condition, the square thread design results in the lowest displacement, while the trapezoidal and Triangular designs yield the highest displacement. Comparing the three figures, it is seen that the quasi-static and static loading conditions yield a similar maximum displacement of the prosthetic and bone regions of the model. However, the dynamic loading condition yields a significant increase in the maximum displacement of all regions of the model for all five thread designs. In square thread implants, the percentage change in maximum displacement because of applying dynamic load is $54 \%$, and $65 \%$ for the rest of the dental implant thread type. Maximum displacement changes attributed to dynamic load in cortical bone were $52.03 \%$ in square thread implants, $41.76 \%$ in triangular thread implants, and $55 \%$ in the other three implants.

Figure 8. Maximum displacements of prosthetic and bone regions of different thread models under a) static loading, b) quasi-static loading, and c) dynamic loading.
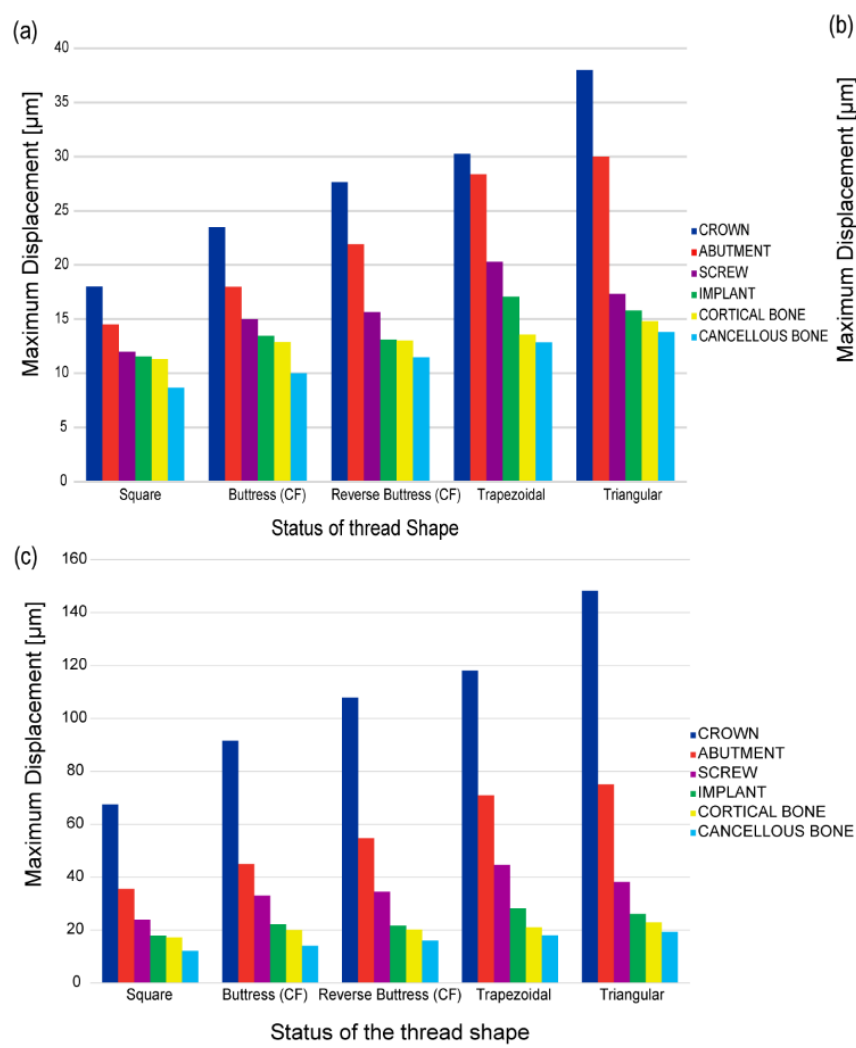

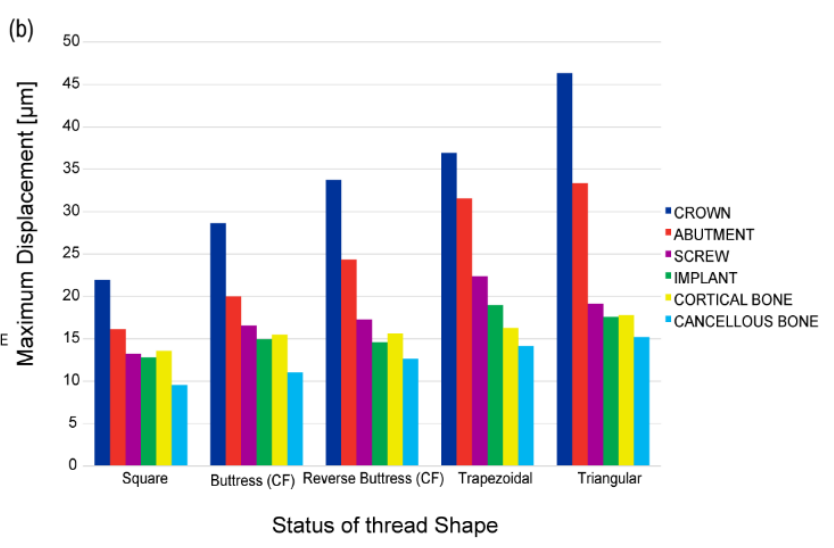


Figure 9(a) shows the maximum pressure (tensile stress and compressive stress) in the square, buttress, reverse buttress, trapezoidal, and triangular thread implant models under dynamic loading conditions. For each of the models, the maximum pressure occurs in the implant neck region, where the implant and cortical bone make contact. The maximum compressive stress is produced in the square and buttress (CF) thread implants, with magnitudes of $360.06 \mathrm{MPa}$ and $365.39 \mathrm{MPa}$ respectively. The addition of a curved flank to a buttress implant increased compressive stress when compared to a square implant. By contrast, the trapezoidal and Triangular thread designs result in relatively lower maximum compressive stresses of $151.88 \mathrm{MPa}$ and $150.55 \mathrm{MPa}$, respectively.

The results confirm that the dynamic loading condition yields a significant increase in the magnitude of the principal stress in all five implant models. The percentage change in minimum and maximum compressive principal stresses due to dynamic loading for buttress thread implant is $51.17 \%$ and $65.26 \%$ and for reverse buttress implant is 39.26 $\%$ and $59.33 \%$, respectively. However, the static and quasi-static loading conditions show no significant difference in effect on the stress response of the implants. The highest maximum principal (tensile) stress occurs in the reverse buttress (CF) model and has a value of $458.35 \mathrm{MPa}$. By contrast, the highest minimum principal (compressive) stress occurs in the buttress thread (CF) model and has a value of $517 \mathrm{MPa}$. For both stresses (tensile and compressive), the maximum stress occurs in the tip bevel region of the implant where it contacts the crestal part of the cortical bone.

Figure 9(c) shows the von Mises stress distributions in the crown, abutment, retaining screw, implant and supporting bone regions of the five models under dynamic loading conditions. As shown in Fig. 9(c), under dynamic loading conditions, the maximum von Mises stress occurs in the implant component of the prosthetic, while the lowest von Mises stress occurs in the spongy bone. The maximum von Mises stress has a value of $496.48 \mathrm{MPa}$ and occurs in the triangular thread model, while the lowest von Mises stress has a value of $159.77 \mathrm{MPa}$ and occurs in the square thread model. Regarding the bone regions of the model, the von Mises stress has maximum values of $81.96 \mathrm{MPa}$ and $24.75 \mathrm{MPa}$ in the cortical bone regions of the triangular and square thread models, respectively, and minimum values of $8.25 \mathrm{MPa}$ and $5.31 \mathrm{MPa}$. 

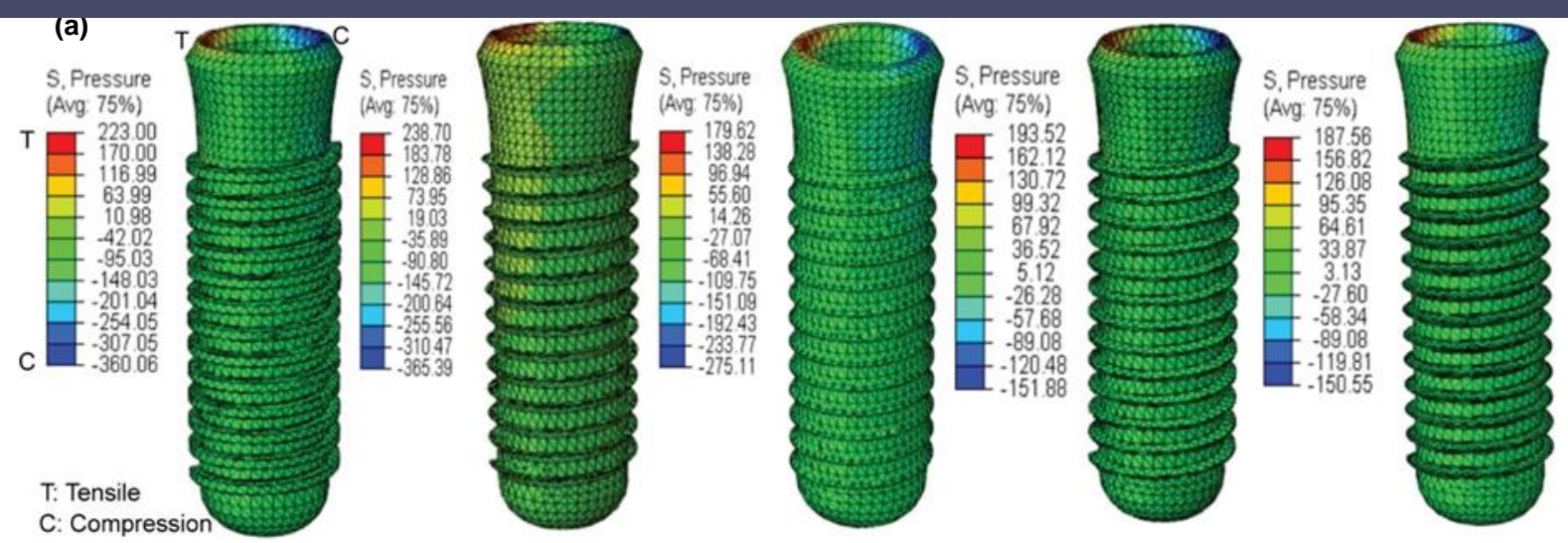

(b)

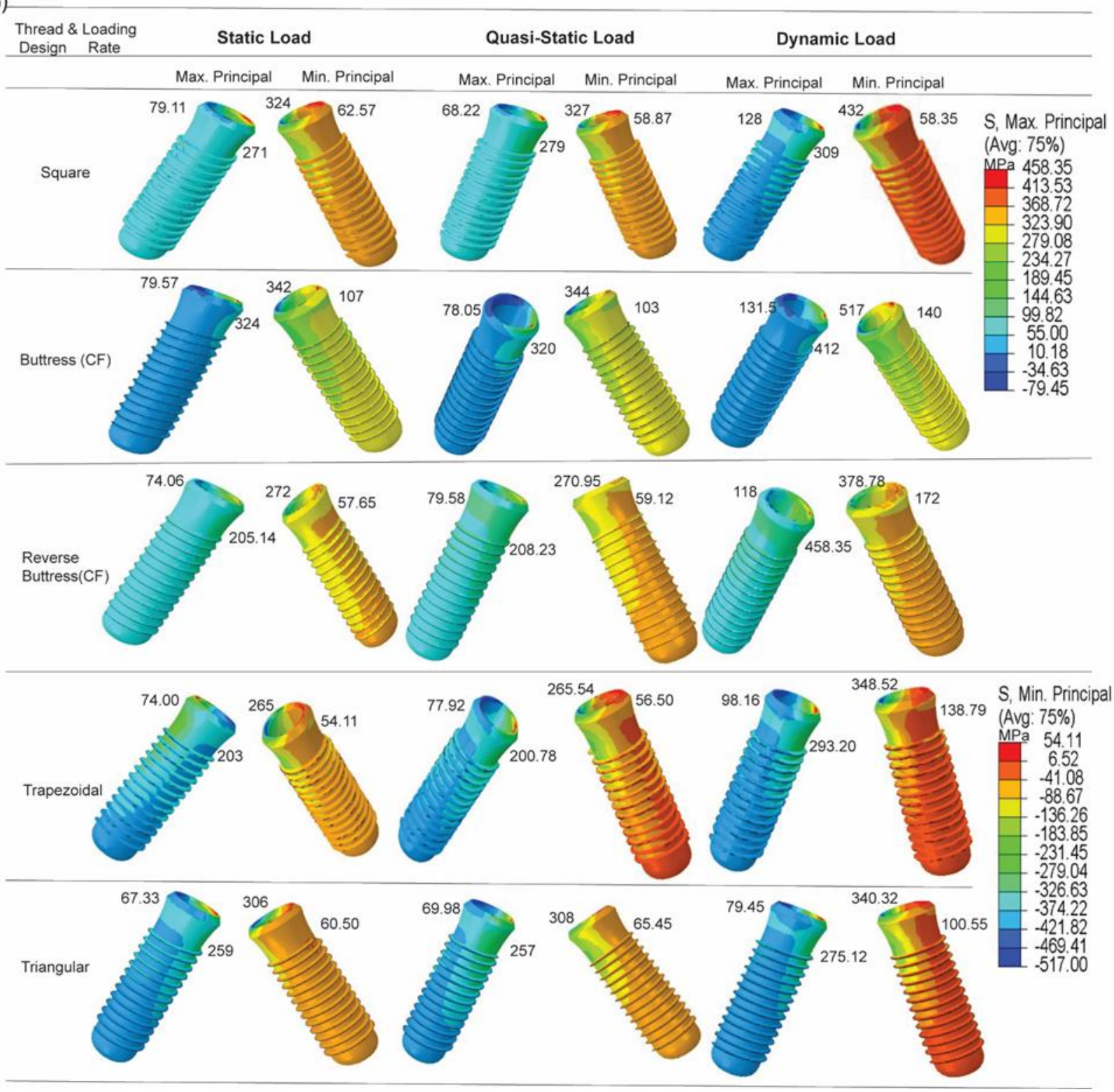


(c)
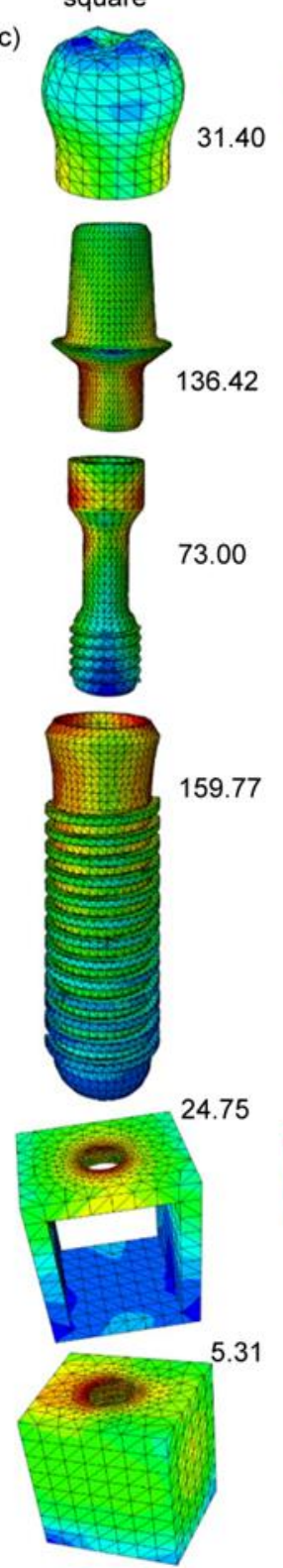
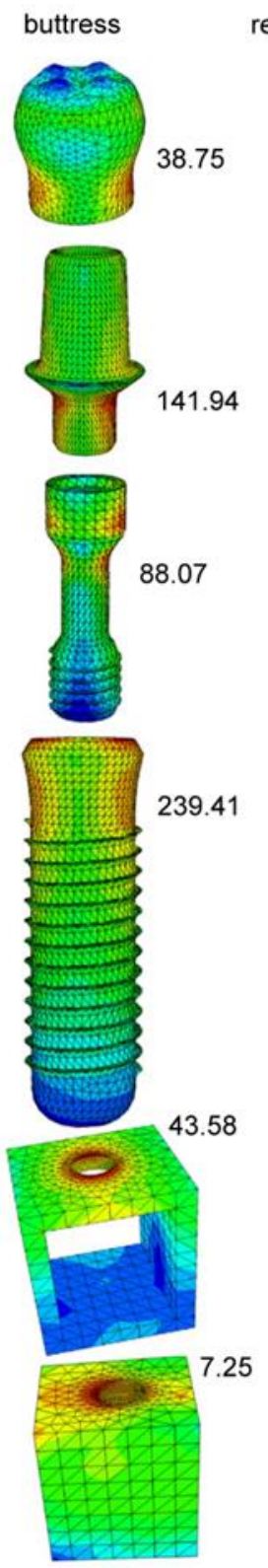
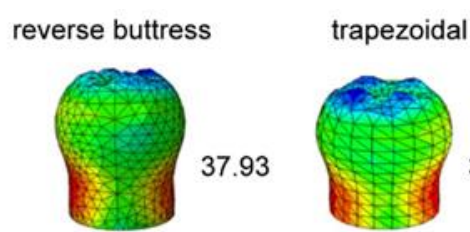

37.17
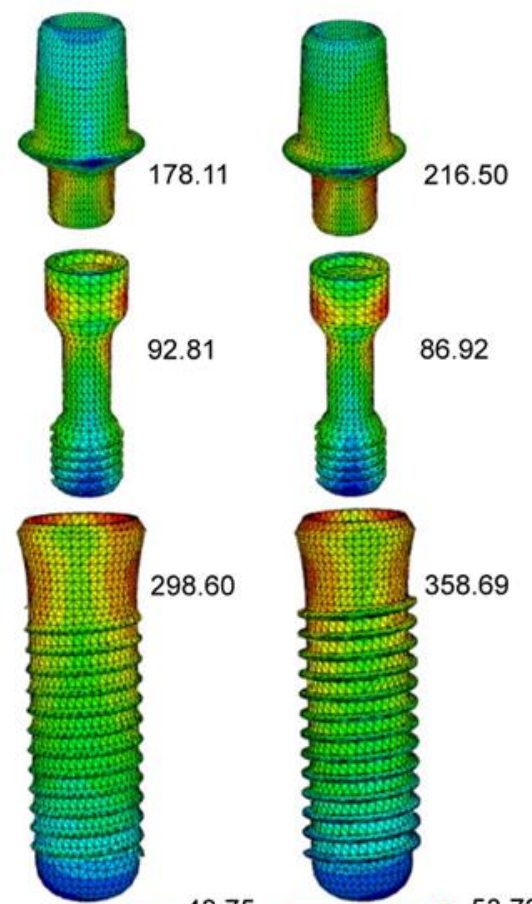

298.60

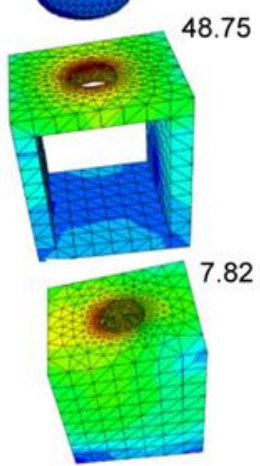

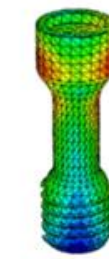

86.92
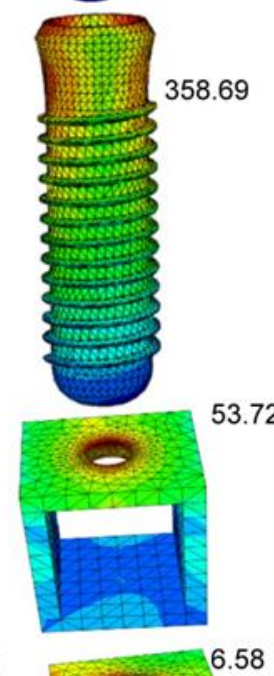

53.72

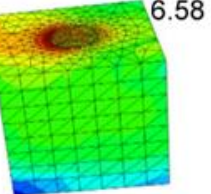

triangular

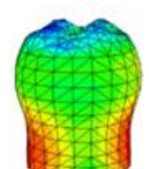

98.58

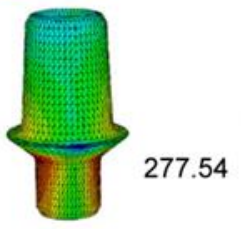

(Avg: $75 \%$

MPa 496

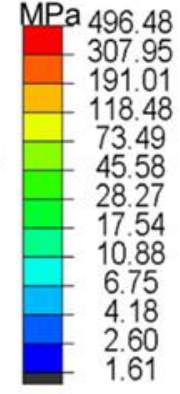

S, Mises (Avg: 75\%)

MPa 5.31

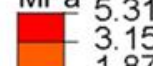

1.87

- 1.11

$-0.66$

0.3

0.14

0.08

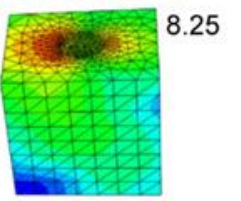
$-0.05$

0.03

0.02

Figure 9. a) Maximum pressure (tensile and compressive stress) in implant, b) maximum and minimum principal stresses in implant, and c) von Mises stress in implants and bone under dynamic load

Table 4 shows the maximum von Mises stress in the crown, abutment, screw, implant, cortical bone and spongy bone regions of the five models under the static, quasi-static and dynamic loading conditions. It is evident that for each region of the model, the maximum von Mises stress increases significantly under the application of a dynamic load. The increases are $32 \%, 38.19 \%, 45.10 \%, 51.20 \%$, and $58.21 \%$ for square, buttress, reverse buttress, trapezoidal, and triangular thread implant, respectively. And Square, buttress, reverse buttress, trapezoidal, and triangular thread implants have a $32 \%, 38.17 \%, 45.08 \%, 51.19 \%$, and 58.19 $\%$ stress increase in cortical bone, respectively. Moreover, for each model, the maximum von Mises stress occurs in the implant region of 
the prosthetic.

Table 4. Maximum von Mises stress in different region of each model under static, quasi-static, and dynamic loads

Table 5 compares the maximum von Mises stresses induced in the buttress and reverse buttress models for different flank designs (curved

\begin{tabular}{|c|c|c|c|c|}
\hline \multicolumn{5}{|c|}{ Maximum Von Mises Stress (MPa) } \\
\hline thread type & components & Static & Quasi-Static & Dynamic \\
\hline \multirow{6}{*}{ square } & CROWN & 23.79 & 24.86 & 31.40 \\
\hline & ABUTMENT & 103.35 & 108.00 & 136.42 \\
\hline & SCREW & 55.30 & 57.79 & 73.00 \\
\hline & IMPLANT & 121.04 & 126.49 & 159.77 \\
\hline & CORTICAL BONE & 18.75 & 19.60 & 24.75 \\
\hline & SPONGY BONE & 4.02 & 4.21 & 5.31 \\
\hline \multirow{6}{*}{ buttress (CF) } & CROWN & 24.29 & 25.56 & 38.75 \\
\hline & ABUTMENT & 110.03 & 115.81 & 141.94 \\
\hline & SCREW & 68.27 & 71.85 & 88.07 \\
\hline & IMPLANT & 173.24 & 182.33 & 239.41 \\
\hline & CORTICAL BONE & 31.54 & 33.19 & 43.58 \\
\hline & SPONGY BONE & 2.25 & 6.23 & 7.25 \\
\hline \multirow{6}{*}{ reverse buttress (CF) } & CROWN & 27.45 & 28.80 & 37.93 \\
\hline & ABUTMENT & 128.88 & 135.22 & 178.11 \\
\hline & SCREW & 67.16 & 70.46 & 92.81 \\
\hline & IMPLANT & 205.79 & 214.42 & 298.60 \\
\hline & CORTICAL BONE & 33.60 & 35.01 & 48.75 \\
\hline & SPONGY BONE & 2.80 & 5.65 & 7.82 \\
\hline \multirow{6}{*}{ trapezoidal } & CROWN & 27.50 & 28.99 & 37.17 \\
\hline & ABUTMENT & 160.13 & 168.86 & 216.50 \\
\hline & SCREW & 64.29 & 67.79 & 86.92 \\
\hline & IMPLANT & 237.23 & 247.06 & 358.69 \\
\hline & CORTICAL BONE & 35.53 & 37.00 & 53.72 \\
\hline & SPONGY BONE & 4.35 & 4.53 & 6.57 \\
\hline \multirow{6}{*}{ triangular } & CROWN & 70.82 & 74.00 & 98.58 \\
\hline & ABUTMENT & 199.38 & 208.36 & 277.54 \\
\hline & SCREW & 98.59 & 103.03 & 137.24 \\
\hline & IMPLANT & 313.81 & 327.93 & 496.48 \\
\hline & CORTICAL BONE & 51.81 & 54.14 & 81.96 \\
\hline & SPONGY BONE & 2.67 & 6.25 & 8.25 \\
\hline
\end{tabular}

and straight) under each of the three loading conditions. It is seen that for each model, the application of a curved flank design lowers the maximum von Mises stress in all the prosthetic and bone regions of the model. The reduction in the maximum von Mises stress is particularly apparent under the dynamic loading condition and in the crown region 
of the prosthetic, for which the reduction is equal to almost $50 \%$. The addition of curved flank (CF) to the buttress and reverse buttress thread profiles will greatly increase compressive stress while significantly lowering tensile stress. After this result is established, only buttress and reverse buttress with CF profile are examined in this study. 
$\begin{array}{lll} & \\ \text { Table 5. Maximum von Mises stress in buttress and reverse buttress models with curved flank (CF) and straight flank (SF) design } \quad 2 & 3\end{array}$

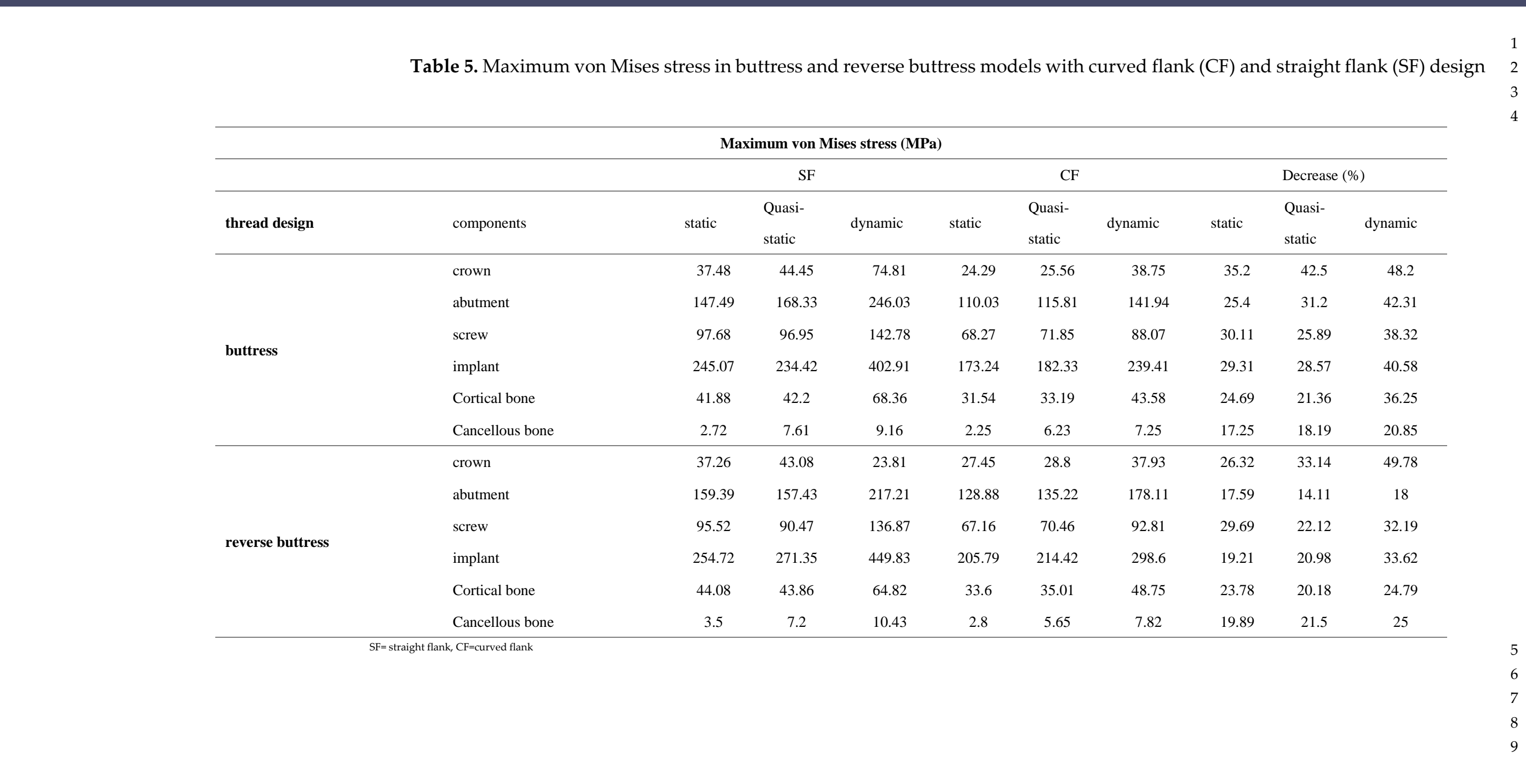

(1)

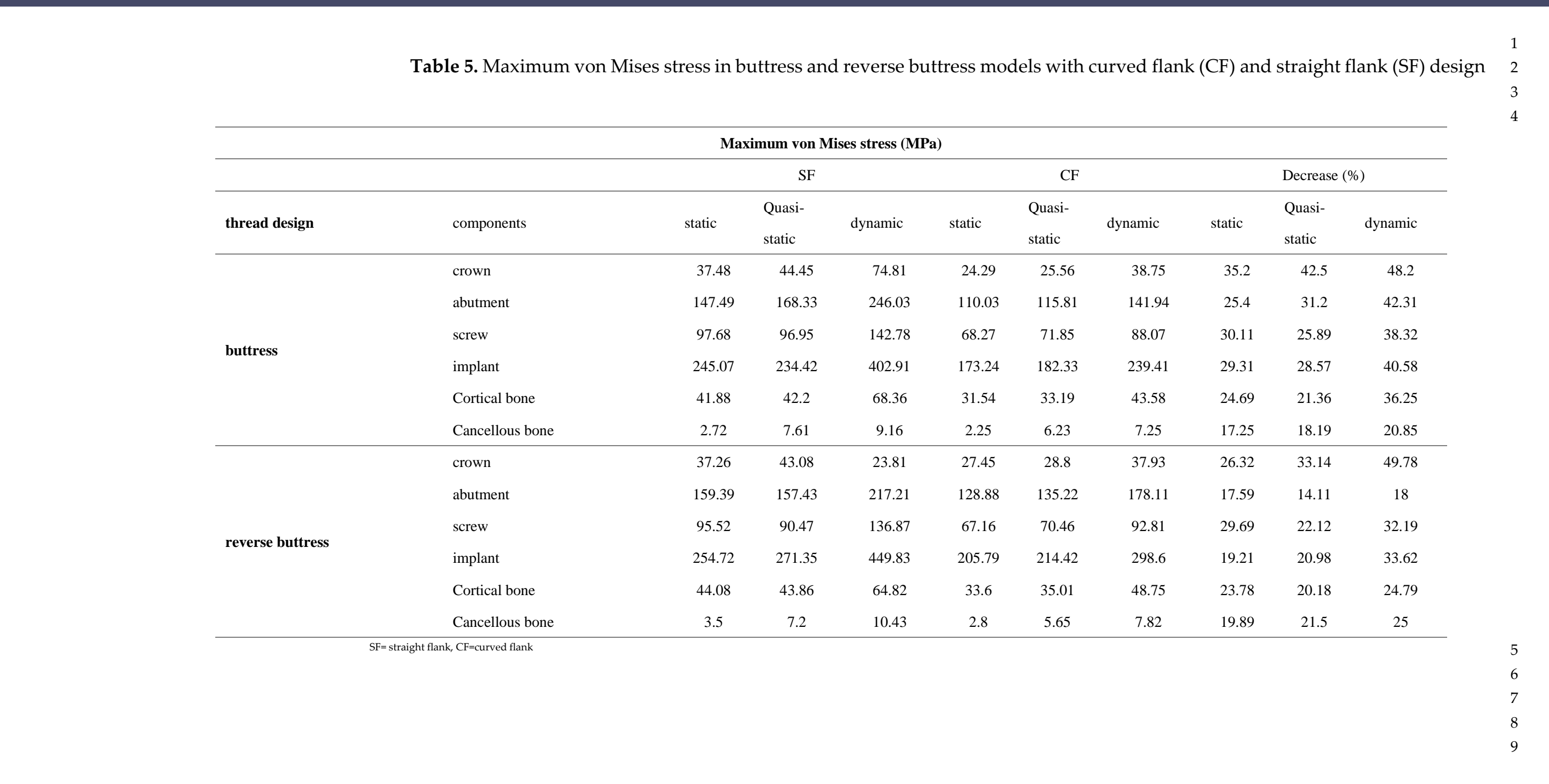




\section{Discussion}

Dynamic mechanical loading can damage the surface morphology and chemistry of dental implants [62], and can result in the penetration of micro-organisms down to the threaded region of the fixture-abutment interface [63]. Furthermore, cyclic loading can increase the stress induced in the implant by around $10-20 \%$ compared to that observed under static loading [43]. Previous studies have shown that the stress induced in the implant and surrounding bone region depends not only on the nature of the applied load (i.e., static or dynamic), but also on the design of the implant thread [64,65].

Accordingly, the present study has performed ABAQUS FEA simulations to investigate the von Mises stress, displacement, shear stress, compressive stress and tensile stress within the implant and surrounding bone for five different thread designs, namely square, buttress, reverse buttress, trapezoidal and triangular, under static, quasi-static and dynamic loading conditions. For the two buttress thread models, both straight and curved flank designs have been considered. For every thread design, a combined load consisting of $23.4 \mathrm{~N}$ in the mesiodistal direction, $17.1 \mathrm{~N}$ in the buccal-lingual direction and 114. $6 \mathrm{~N}$ in the apical direction has been applied at a dummy reference point located at $3 \mathrm{~mm}$ from the occlusal surface. Moreover, the implanted bone has been modeled as an anisotropic structure consisting of a spongy bone interior and a compact bone exterior.

It has been shown that for all five thread design models, the von Mises stress, shear stress, compressive stress, and displacement all increase significantly under a dynamic load compared to a static or quasi-static load. However, little difference has been observed in the stress response of the implant under static and quasi-static loads, respectively. In general, the results have shown that the maximum stress is concentrated in the contact areas of the implant-bone models, e.g., at the abutment-screw, abutment-implant and bone-implant interfaces (see Figs. 7 and 9). Accordingly, for all thread designs, there is a risk of micromotion, which may cause screw loosening, crestal bone loss, and implant fracture. The present results have shown that, under dynamic loading, the maximum von Mises stress in the prosthetic components is higher under buccal-lingual loading than under axial or mesiodistal loading (see Figs. 7(a)-7(d)). By contrast, in the cortical and spongy bone regions, the maximum von Mises stress is produced under axial compressive loading (see Figs. 7(e)-(f)).

The results presented in Fig. 9(b) have shown that the maximum principal stress is concentrated in the first thread of the implant in the tip bevel region where it contacts the crestal part of the cortical bone. This prediction is consistent with the findings of Sun et al. [66] that the abutment screw commonly breaks at the first thread and the implant breaks in the neck region. The simulation results obtained for the maximum shear stress (Table 3) have shown no significant differences in the stress response behaviors of the five thread models under static loads and quasi-static loads, respectively. However, for each model, the stress increases significantly under dynamic loading. When all implant models were considered, it increased by $30-60 \%$ (see Table 4 and Fig 9(c)). This is extremely important, because it implies that such cyclic loading rates must be closely monitored, since they may cause implant and bone fatigue and fracture. Many previous studies have reported that dynamic loading can have a greater effect on the implant success rate than static loading. For example, Yagihara et al. [59] compared the effects of static and dynamic loads on the performance of implants in rat left tibia after four and eight weeks, and found that the attachment strength was significantly improved following the application of a dynamic load for four weeks compared to that obtained under a static load after four or eight weeks. Likewise, Duyck et al. [67] reported that the periimplant bone resorption performance in rabbit tibias was markedly better under dynamic load conditions than under static loads. However, very few studies have applied FEA to examine the effects of dynamic loading on dental implants $[11,39,43,58,59,68]$.

The results obtained in the present study have shown that the application of dynamic loading can increases the stress of dental implants and cortical bone by as much as 30 - 
$60 \%$ compared to static loading (see Table 4 and Fig 9(c)). This percentage increment is obtained when considering all the five implant models. And most importantly, including buttress and reverse buttress implant with CF thread profiles. In previous studies it is only studied considering one thread type dental implant. This finding is inconsistent with that of Kayabaşi et al. [43], who reported that dynamic loading may increase the stress in dental implants by 10-20\%. However, Kayabaşi et al. [43] considered only a single dental thread design (reverse buttress), whereas the present study has considered five different models. Hence our conclusion is based on the result from five implant thead type. In general, the present results have shown that while dynamic loading yields an effective increase in the compressive stress in the implant and bone region and is therefore beneficial in improving the implant success rate, the thread design should be carefully chosen to avoid failure in the first thread region of the implant.

The FEA results obtained in the present study have shown that, for all the loading rates and thread designs, the maximum von Mises stress is concentrated in the implant region of the prosthetic (see Table 4 and Fig 9(c)). As a result, the minimum stress is transferred to the bone, and the uniformity of the stress distribution within the bone is improved. The present results are thus in good general agreement with those of previous studies [34,43,69-72]. However, most previous studies did not consider the crown and abutment screw components of the prosthetic [34,69,71,72], and hence the clinical application of the FEA findings is somewhat limited. Furthermore, previous studies have generally considered only a static masticatory load, [34,73-81]. However, in addition to static load, the current study considered quasi-static and dynamic loading rates. As a result, this research yields better results and a more reliable conclusion. This also reveals that dynamic loading considerably increases stress in all five models and cortical bone, potentially leading to bone fatigue and fracture. The present results have shown that the implant thread design affects both the magnitude and the distribution of the stress induced in the cortical bone under all three loading rates (see Table 4 and Fig. 9C). They are thus in good agreement with the findings of Hansson and Werke [46]. In particular, the results have shown that for the buttress and reverse buttress thread models, the application of curved flanks reduces the maximum von Mises stress by up to $50 \%$ compared to straight flanks (Table 5), curved flank provides more bone contact area by decreasing the shear stress and tensile stress. Hence, more bone contact area has been proven to offer increased initial stability and stress resistance [82].

Among the various thread designs considered in the present study, the square thread design results in the lowest von Mises stress, shear stress and displacement, and the highest compressive stress (see Fig. 8, Fig.9(b), Table 3 and Table 4). In general, the masticatory load acting on the crown occlusal surface results in three different stresses, namely tensile, compressive and shear. Tensile stresses tend to pull objects apart and if it becomes more than the yield strength, it may cause failure in implant and bone loss, while shear forces promote sliding. By contrast, compressive stresses maintain the integrity of the bone-implant interface. Furthermore cortical bone is the strongest in compression and the weakest in shear [83]. Thus, the present results suggest that the square thread design, which enhances the compressive stress, is the most suitable for dental implant applications. However, the buttress and reverse buttress designs with curved flanks also reduce the tensile and shear stress, while also promotes the compressive stress (see Fig. 9 and Table 5). Consequently, the buttress thread designs with curved flanks also represent a favorable design for dental implants. Furthermore, for each design, the maximum displacement, von Mises stress, and shear stress are significantly lower in the spongy bone region than in the cortical bone region (see Figs. 8, 9 and Table 3). 


\section{Conclusion}

This study has performed a comprehensive finite element analysis (FEA) investigation into the effects of the loading rate (static, quasi-static and dynamic) and thread design (square, buttressed, reverse buttressed, trapezoidal, and triangular) on the stress response of dental prosthetics implanted in anisotropic bone.

Overall, the simulation results support the following main conclusions:

- The application of dynamic masticatory loading to the occlusal surface of the prosthetic increases the stress within the implant and surrounding bone region by as much as $30-60 \%$. Thus, while static loading analyses provide a convenient and low-complexity approach for performing the preliminary design of dental implants, dynamic loading analyses are required to properly understand the performance implications of the proposed design in actual clinical situations.

- For the buttress and reverse buttress thread designs, the application of a curved flank profile reduces the induced stress by as much as $50 \%$ compared to that of a straight flank profile design under dynamic loading conditions.

- Among the various thread design models considered in the present study, the square thread model reduces the von Mises stress, shear stress and displacement magnitude, and increases the compressive stress. Therefore, it represents the most favorable thread design model for practical applications.

- No significant difference exists between the stress response behavior of the different thread design models under static loading and quasi-static loading conditions, respectively.

- For each of the considered design models, the maximum displacement, von Mises stress, and shear stress are significantly lower in the spongy bone region than in the cortical bone region.

In conclusion, stable osseointegration and a uniform stress distribution are more responsive to the implant design in the human jawbone than in other bones [84]. Hence, a proper understanding of the stress response of dental prosthetics and the surrounding bone region is essential in improving the implant success rate. In general, FEM provides an attractive approach for analyzing biomechanical processes which are difficult (or impossible) to examine in vivo or in vitro. However, the practical applicability of the FEM results depends fundamentally on the accuracy of the FEM model and the representativeness of the considered loading conditions. Accordingly, the present study has not only considered three different loading scenarios (static, quasi-static and dynamic), but also a combined loading condition in the buccal-lingual, mesiodistal and axial directions, respectively. Moreover, the simulations have analyzed the detailed stress response within each of the individual components within the prosthetic (crown, abutment, screw, and implant), and have considered the bone to have an anisotropic structure consisting of a cortical bone exterior and a spongy bone interior. Thus, the FEA results are expected to more closely mimic actual clinical conditions, and to provide more meaningful insights into the likely success rate of the implant accordingly. Future studies might usefully validate the numerical findings reported in this study through animal studies.

\footnotetext{
Author Contributions: For research articles with several authors, a short paragraph specifying their individual contributions must be provided. The following statements should be used "Conceptualization, Dawit-Bogale Alemayehu \& Yeau-Ren Jeng .; methodology, Dawit-Bogale Alemayehu; software, Dawit-Bogale Alemayehu; validation, Dawit-Bogale Alemayehu; formal analysis, Dawit-Bogale Alemayehu; investigation, Dawit-Bogale Alemayehu.; resources, Dawit-Bogale Alemayehu \& Yeau-Ren Jeng.; data curation, Dawit-Bogale Alemayehu.; writing-original draft preparation, Dawit-Bogale Alemayehu; writing-review and editing, Dawit-Bogale Alemayehu \& Yeau-Ren Jeng.; visualization, Dawit-Bogale Alemayehu.; supervision, Yeau-Ren Jeng.; project administration, Yeau-Ren Jeng.; funding acquisition, Yeau-Ren Jeng.
} 
Funding: This work was financially supported by the Ministry of Science and Technology of Taiwan (MOST 108-2221-E-006-228-MY3, 109-2923-E-006-005-MY3 and 110-2124-M-006-005) and Air Force Office of Science Research (AFOSR) under contract no. FA4869- 06-1-0056 AOARD 064053.

Institutional Review Board Statement: Not applicable.

Informed Consent Statement: Not applicable.

Acknowledgments: Professor Yeau-Ren Jeng would like to acknowledge Medical Device Innovation Center (MDIC) and Intelligent Manufacturing Research Center (iMRC) from The Featured Areas Research Center Program within the framework of the Higher Education Sprout Project by the Ministry of Education (MOE) in Taiwan and AC2T research GmbH (AC2T) in Austria (COMET InTribology, FFG-No.872176).

Conflicts of Interest: The authors declare no conflict of interest.

\section{References}

1. Yang, B.; Irastorza-Landa, A.; Heuberger, P.; Ploeg, H.L. Effect of insertion factors on dental implant insertion torque/energyexperimental results. J. Mech. Behav. Biomed. Mater. 2020, 112, 103995, doi:10.1016/j.jmbbm.2020.103995.

2. Li, J.; Jansen, J.A.; Walboomers, X.F.; van den Beucken, J.J. Mechanical aspects of dental implants and osseointegration: A narrative review. J. Mech. Behav. Biomed. Mater. 2020, 103, 103574, doi:10.1016/j.jmbbm.2019.103574.

3. Brune, A.; Stiesch, M.; Eisenburger, M.; Greuling, A. The effect of different occlusal contact situations on peri-implant bone stress - A contact finite element analysis of indirect axial loading. Mater. Sci. Eng. C 2019, 99, 367-373, doi:10.1016/j.msec.2019.01.104.

4. Cantó-Navés, O.; Marimon, X.; Ferrer, M.; Cabratosa-Termes, J. Comparison between experimental digital image processing and numerical methods for stress analysis in dental implants with different restorative materials. J. Mech. Behav. Biomed. Mater. 2021, 113, doi:10.1016/j.jmbbm.2020.104092.

5. Shamami, D.Z.; Karimi, A.; Beigzadeh, B.; Derakhshan, S.; Navidbakhsh, M. A Three-Dimensional Finite Element Study to Characterize the Influence of Load Direction on Stress Distribution in Bone Around Dental Implant. J. Biomater. Tissue Eng. 2014, 4, 693-699, doi:10.1166/jbt.2014.1230.

6. Wu, T.; Fan, H.; Ma, R.; Chen, H.; Li, Z.; Yu, H. Effect of lubricant on the reliability of dental implant abutment screw joint: An in vitro laboratory and three-dimension finite element analysis. Mater. Sci. Eng. C 2017, 75, 297-304, doi:10.1016/j.msec.2016.11.041.

7. Silva, G.A.F.; Faot, F.; Possebon, A.P. da R.; da Silva, W.J.; Del Bel Cury, A.A. Effect of macrogeometry and bone type on insertion torque, primary stability, surface topography damage and titanium release of dental implants during surgical insertion into artificial bone. J. Mech. Behav. Biomed. Mater. 2021, 119, doi:10.1016/j.jmbbm.2021.104515.

8. Macedo, J.P.; Pereira, J.; Faria, J.; Pereira, C.A.; Alves, J.L.; Henriques, B.; Souza, J.C.M.; López-López, J. Finite element analysis of stress extent at peri-implant bone surrounding external hexagon or Morse taper implants. J. Mech. Behav. Biomed. Mater. 2017, 71, 441-447, doi:10.1016/j.jmbbm.2017.03.011.

9. Lee, C.C.; Lin, S.C.; Kang, M.J.; Wu, S.W.; Fu, P.Y. Effects of implant threads on the contact area and stress distribution of marginal bone. J. Dent. Sci. 2010, 5, 156-165, doi:10.1016/S1991-7902(10)60023-2.

10. Djebbar, N.; Serier, B.; Bouiadjra, B.B.; Benbarek, S.; Drai, A. Analysis of the effect of load direction on the stress distribution in dental implant. Mater. Des. 2010, 31, 2097-2101, doi:10.1016/j.matdes.2009.10.042.

11. Merdji, A.; Bachir Bouiadjra, B.; Ould Chikh, B.; Mootanah, R.; Aminallah, L.; Serier, B.; Muslih, I.M. Stress distribution in dental prosthesis under an occlusal combined dynamic loading. Mater. Des. 2012, 36, 705-713, doi:10.1016/j.matdes.2011.12.006.

12. Ausiello, P.; Franciosa, P.; Martorelli, M.; Watts, D.C. Effects of thread features in osseo-integrated titanium implants using 
a statistics-based finite element method. Dent. Mater. 2012, 28, 919-927, doi:10.1016/j.dental.2012.04.035.

13. Reddy, P.M.; Thumati, P. A 3-D fi nite element analysis of strain around end osseous threaded and non-threaded implantopposing natural teeth with regular occlusion and altered occlusion: An in - vitro study. 2014, 4, doi:10.4103/09746781.131001.

14. Pirmoradian, M.; Naeeni, H.A.; Firouzbakht, M.; Toghraie, D.; khabaz, M.K.; Darabi, R. Finite element analysis and experimental evaluation on stress distribution and sensitivity of dental implants to assess optimum length and thread pitch. Comput. Methods Programs Biomed. 2020, 187, 105258, doi:10.1016/j.cmpb.2019.105258.

15. Abuhussein, H.; Pagni, G.; Rebaudi, A.; Wang, H.L. The effect of thread pattern upon implant osseointegration: Review. Clin. Oral Implants Res. 2010, 21, 129-136, doi:10.1111/j.1600-0501.2009.01800.x.

16. Niroomand, M.R.; Arabbeiki, M. Implant stability in different implantation stages: Analysis of various interface conditions. Informatics Med. Unlocked 2020, 19, 100317, doi:10.1016/j.imu.2020.100317.

17. Gasik, M.; Lambert, F.; Bacevic, M. Biomechanical properties of bone and mucosa for design and application of dental implants. Materials (Basel). 2021, 14, doi:10.3390/ma14112845.

18. Achour, T.; Merdji, A.; Bachir Bouiadjra, B.; Serier, B.; Djebbar, N. Stress distribution in dental implant with elastomeric stress barrier. Mater. Des. 2011, 32, 282-290, doi:https://doi.org/10.1016/j.matdes.2010.05.053.

19. Marcián, P.; Borák, L.; Zikmund, T.; Horáčková, L.; Kaiser, J.; Joukal, M.; Wolff, J. On the limits of finite element models created from (micro)CT datasets and used in studies of bone-implant-related biomechanical problems. J. Mech. Behav. Biomed. Mater. 2021, 117, doi:10.1016/j.jmbbm.2021.104393.

20. Wirth, A.J.; Müller, R.; Harry van Lenthe, G. The discrete nature of trabecular bone microarchitecture affects implant stability. J. Biomech. 2012, 45, 1060-1067, doi:https://doi.org/10.1016/j.jbiomech.2011.12.024.

21. Mao, Q.; Su, K.; Zhou, Y.; Hossaini-Zadeh, M.; Lewis, G.S.; Du, J. Voxel-based micro-finite element analysis of dental implants in a human cadaveric mandible: Tissue modulus assignment and sensitivity analyses. J. Mech. Behav. Biomed. Mater. 2019, 94, 229-237, doi:10.1016/j.jmbbm.2019.03.008.

22. Zhang, G.; Yuan, H.; Chen, X.; Wang, W.; Chen, J.; Liang, J.; Zhang, P. A three-dimensional finite element study on the biomechanical simulation of various structured dental implants and their surrounding bone tissues. Int. J. Dent. 2016, doi:10.1155/2016/4867402.

23. Rendohl, E.D.S.; Brandt, W.C. Stress distribution with extra-short implants in an angled frictional system : A fi nite element analysis study. J. Prosthet. Dent. 2020, 120, 1-9, doi:10.1016/j.prosdent.2020.04.022.

24. Aslam, A.; Hassan, S.H.; Aslam, H.M.; Khan, D.A. Effect of platform switching on peri-implant bone: A 3D finite element analysis. J. Prosthet. Dent. 2019, 121, 935-940, doi:10.1016/j.prosdent.2018.08.011.

25. Borges Radaelli, M.T.; Idogava, H.T.; Spazzin, A.O.; Noritomi, P.Y.; Boscato, N. Parafunctional loading and occlusal device on stress distribution around implants: A 3D finite element analysis. J. Prosthet. Dent. 2018, 120, 565-572, doi:10.1016/j.prosdent.2017.12.023.

26. Cinel, S.; Celik, E.; Sagirkaya, E.; Sahin, O. Experimental evaluation of stress distribution with narrow diameter implants: A finite element analysis. J. Prosthet. Dent. 2018, 119, 417-425, doi:10.1016/j.prosdent.2017.04.024.

27. Dimililer, G.; Kücükkurt, S.; Cetiner, S. Biomechanical effects of implant number and diameter on stress distributions in maxillary implant-supported overdentures. J. Prosthet. Dent. 2018, 119, 244-249.e6, doi:10.1016/j.prosdent.2017.03.016.

28. Moraes, S.L.D.; Pellizzer, E.P.; Verri, F.R.; Santiago, J.F.; Silva, J.V.L. Three-dimensional finite element analysis of stress distribution in retention screws of different crown-implant ratios. Comput. Methods Biomech. Biomed. Engin. 2015, 18, 689-696, doi:10.1080/10255842.2013.820719.

29. Pisani, M.X.; Presotto, A.G.C.; Mesquita, M.F.; Barão, V.A.R.; Kemmoku, D.T.; Del Bel Cury, A.A. Biomechanical behavior of 2-implant- and single-implant-retained mandibular overdentures with conventional or mini implants. J. Prosthet. Dent. 2018, 120, 421-430, doi:10.1016/j.prosdent.2017.12.012.

30. Ramos Verri, F.; Santiago Junior, J.F.; de Faria Almeida, D.A.; de Oliveira, G.B.B.; de Souza Batista, V.E.; Marques Honório, 
H.; Yoshito Noritomi, P.; Piza Pellizzer, E. Biomechanical influence of crown-to-implant ratio on stress distribution over internal hexagon short implant: 3-D finite element analysis with statistical test. J. Biomech. 2015, 48, 138-145, doi:10.1016/j.jbiomech.2014.10.021.

31. Maria, E.; Ciaramella, S.; Calì, M.; Pascoletti, G.; Martorelli, M.; Asero, R.; Watts, D.C. Modal analysis for implant stability assessment: Sensitivity of this methodology for different implant designs. Dent. Mater. 2018, 34, 1235-1245, doi:10.1016/j.dental.2018.05.016.

32. Narendrakumar, U.; Mathew, A.T.; Iyer, N.; Rahman, F.; Manjubala, I. A 3D Finite Element Analysis of Dental Implants with Varying Thread Angles. Mater. Today Proc. 2018, 5, 11900-11905, doi:10.1016/j.matpr.2018.02.163.

33. Kaleli, N.; Sarac, D.; Külünk, S.; Öztürk, Ö. Effect of different restorative crown and customized abutment materials on stress distribution in single implants and peripheral bone: A three-dimensional fi nite element analysis study. J. Prosthet. Dent. 2018, 119, 437-445, doi:10.1016/j.prosdent.2017.03.008.

34. Mosavar, A.; Ziaei, A.; Kadkhodaei, M. The Effect of Implant Thread Design on Stress Distribution in Anisotropic Bone with Different Osseointegration Conditions: A Finite Element Analysis. Int. J. Oral Maxillofac. Implants 2015, 30, 1317-1326, doi:10.11607/jomi.4091.

35. Amaral, C.F.; Gomes, R.S.; Rodrigues Garcia, R.C.M.; Del Bel Cury, A.A. Stress distribution of single-implant-retained overdenture reinforced with a framework: A finite element analysis study. J. Prosthet. Dent. 2018, 119, 791-796, doi:10.1016/j.prosdent.2017.07.016.

36. Khosravani, M.R. Mechanical behavior of restorative dental composites under various loading conditions. J. Mech. Behav. Biomed. Mater. 2019, 93, 151-157, doi:10.1016/j.jmbbm.2019.02.009.

37. Marci, P.; Kaiser, J. Micro fi nite element analysis of dental implants under different loading conditions. 2018, 96, 157-165, doi:10.1016/j.compbiomed.2018.03.012.

38. Huang, M.; Juan, P.; Chen, S.; Wu, C.; Wen, S. Materials Science \& Engineering C The potential of the three-dimensional printed titanium mesh implant for cranioplasty surgery applications : Biomechanical behaviors and surface properties. Mater. Sci. Eng. C 2019, 97, 412-419, doi:10.1016/j.msec.2018.11.075.

39. Bulaqi, H.A.; Mousavi Mashhadi, M.; Safari, H.; Samandari, M.M.; Geramipanah, F. Effect of increased crown height on stress distribution in short dental implant components and their surrounding bone: A finite element analysis. J. Prosthet. Dent. 2015, 113, 548-557, doi:10.1016/j.prosdent.2014.11.007.

40. Gotfredsen, K.; Berglundh, T.; Lindhe, J. Bone reactions adjacent to titanium implants subjected to static load. A study in the dog (I). Clin. Oral Implants Res. 2001, 12, 1-8, doi:10.1034/j.1600-0501.2001.012001001.x.

41. Gotfredsen, K.; Berglundh, T.; Lindhe, J. Bone reactions adjacent to titanium implants subjected to static load of different duration. A study in the dog (III). Clin. Oral Implants Res. 2001, 12, 552-558, doi:10.1034/j.1600-0501.2001.120602.x.

42. Gotfredsen, K.; Berglundh, T.; Lindhe, J. Bone reactions adjacent to titanium implants with different surface characteristics subjected to static load. A study in the dog (II). Clin. Oral Implants Res. 2001, 12, 196-201, doi:10.1034/j.16000501.2001.012003196.x.

43. Kayabaşi, O.; Yüzbasioğlu, E.; Erzincanli, F. Static, dynamic and fatigue behaviors of dental implant using finite element method. Adv. Eng. Softw. 2006, 37, 649-658, doi:10.1016/j.advengsoft.2006.02.004.

44. Gehrke, S.A.; Pérez-Díaz, L.; Dedavid, B.A. Quasi-static strength and fractography analysis of two dental implants manufactured by direct metal laser sintering. Clin. Implant Dent. Relat. Res. 2018, 20, 368-374, doi:10.1111/cid.12590.

45. Lofaj, F.; Ku, J.; Németh, D.; Kvetková, L. Finite element analysis of stress distributions in mono- and bi-cortical dental implants. 2015, 50, 85-96, doi:10.1016/j.msec.2015.01.095.

46. Hansson, S.; Werke, M. The implant thread as a retention element in cortical bone: The effect of thread size and thread profile: A finite element study. J. Biomech. 2003, doi:10.1016/S0021-9290(03)00164-7.

47. Ryu, H.S.; Namgung, C.; Lee, J.H.; Lim, Y.J. The influence of thread geometry on implant osseointegration under immediate loading: A literature review. J. Adv. Prosthodont. 2014, 6, 547-554, doi:10.4047/jap.2014.6.6.547. 
48. Misch, C.; Strong, J.; Bidez, M.W. Scientific Rationale for Dental Implant Design. In Contemporary Implant Dentistry; St Louis: Mosby, 2015; pp. 200-229.

49. Bumgardner, J.D.; Boring, J.G.; Cooper, R.C.J.; Gao, C.; Givaruangsawat, S.; Gilbert, J.A.; Misch, C.M.; Steflik, D.E. Preliminary evaluation of a new dental implant design in canine models. Implant Dent. 2000, 9, 252-260, doi:10.1097/00008505200009030-00011.

50. Barbier, L.; Schepers, E. Adaptive bone remodeling around oral implants under axial and nonaxial loading conditions in the dog mandible. Int. J. Oral Maxillofac. Implants 1997, 12, 215-223.

51. Albrektsson, T.; Brånemark, P.I.; Hansson, H.A.; Kasemo, B.; Larsson, K.; Lundström, I.; McQueen, D.H.; Skalak, R. The interface zone of inorganic implants In vivo: Titanium implants in bone. Ann. Biomed. Eng. 1983, 11, 1-27, doi:10.1007/BF02363944.

52. Jeng, Y.R.; Lin, T.T.; Hsu, H.M.; Chang, H.J.; Shieh, D. Bin Human enamel rod presents anisotropic nanotribological properties. J. Mech. Behav. Biomed. Mater. 2011, 4, 515-522, doi:10.1016/j.jmbbm.2010.12.002.

53. Chen, L.J.; He, H.; Li, Y.M.; Li, T.; Guo, X.P.; Wang, R.F. Finite element analysis of stress at implant-bone interface of dental implants with different structures. Trans. Nonferrous Met. Soc. China (English Ed. 2011, 21, 1602-1610, doi:10.1016/S10036326(11)60903-5.

54. Linetskiy, I.; Demenko, V.; Linetska, L.; Yefremov, O. Impact of annual bone loss and different bone quality on dental implant success - A finite element study. Comput. Biol. Med. 2017, 91, 318-325, doi:10.1016/j.compbiomed.2017.09.016.

55. de la Rosa Castolo, G.; Guevara Perez, S. V.; Arnoux, P.J.; Badih, L.; Bonnet, F.; Behr, M. Implant-supported overdentures with different clinical configurations: Mechanical resistance using a numerical approach. J. Prosthet. Dent. 2019, 121, 546.e1546.e10, doi:10.1016/j.prosdent.2018.09.023.

56. Hussein, F.A.; Salloomi, K.N.; Abdulrahman, B.Y.; Al-Zahawi, A.R.; Sabri, L.A. Effect of thread depth and implant shape on stress distribution in anterior and posterior regions of mandible bone: A finite element analysis. Dent. Res. J. (Isfahan). 2019, 16, 200-207, doi:10.4103/1735-3327.255745.

57. Dastenaei, F.M.; Hajarian, A.; Zargar, O.; Zand, M.M.; Noorollahian, S. Effects of thread shape on strength and stability of dental miniscrews against orthodontic forces. Procedia Manuf. 2019, 35, 1032-1038, doi:10.1016/j.promfg.2019.06.053.

58. Geramizadeh, M.; Katoozian, H.; Amid, R.; Kadkhodazadeh, M. Finite element analysis of dental implants with and without microthreads under static and dynamic loading. J. Long. Term. Eff. Med. Implants 2017, 27, 25-35, doi:10.1615/JLONGTERMEFFMEDIMPLANTS.2017020007.

59. Yagihara, A.; Kawasaki, R.; Mita, A.; Takakuda, K. Impact of Dynamic and Static Load on Bone Around Implants: An Experimental Study in a Rat Model. Int. J. Oral Maxillofac. Implants 2016, e49-e56, doi:10.11607/jomi.4372.

60. Po, J.M.C.; Kieser, J.A.; Gallo, L.M.; Tésenyi, A.J.; Herbison, P.; Farella, M. Time-frequency analysis of chewing activity in the natural environment. J. Dent. Res. 2011, 90, 1206-1210, doi:10.1177/0022034511416669.

61. Tang, C.B.; Liu, S.Y.; Zhou, G.X.; Yu, J.H.; Zhang, G.D.; Bao, Y.D.; Wang, Q.J. Nonlinear finite element analysis of three implant-abutment interface designs. Int. J. Oral Sci. 2012, 4, 101-108, doi:10.1038/ijos.2012.35.

62. Sridhar, S.; Wang, F.; Wilson, T.G.; Palmer, K.; Valderrama, P.; Rodrigues, D.C. The role of bacterial biofilm and mechanical forces in modulating dental implant failures. J. Mech. Behav. Biomed. Mater. 2019, 92, 118-127, doi:10.1016/j.jmbbm.2019.01.012.

63. Koutouzis, T.; Mesia, R.; Calderon, N.; Wong, F.; Wallet, S. The effect of dynamic loading on bacterial colonization of the dental implant fixture-abutment interface: An in vitro study. J. Oral Implantol. 2014, 40, 432-437, doi:10.1563/AAID-JOI-D-1100207.

64. Walid, M.A.; Almutairi, A.S.; Alkhodary, M.A. The effect of osseodensification and different thread designs on the dental implant primary stability [ version 1 ; peer review : 2 approved , 1 approved with reservations ] Abdullah Saleh Almutairi Referee Status : F1000Research 2019, 1-10.

65. Calì, M.; Zanetti, E.M.; Oliveri, S.M.; Asero, R.; Ciaramella, S.; Martorelli, M.; Bignardi, C. Influence of thread shape and inclination on the biomechanical behaviour of plateau implant systems. Dent. Mater. 2018, 34, 460-469, 
doi:10.1016/j.dental.2018.01.012.

66. Sun, F.; Wang, L.; Li, X.C.; Cheng, W.; Lin, Z.; Ba, D.C.; Song, G.Q.; Sun, C.S. Effect of surface modification on the long-term stability of dental implant abutment screws by plasma nitriding treatment. Surf. Coatings Technol. 2020, 399, 126089, doi:10.1016/j.surfcoat.2020.126089.

67. Duyck, J.; Rønold, H.J.; Van Oosterwyck, H.; Naert, I.; Sloten, J. Vander; Ellingsen, J.E. The influence of static and dynamic loading on marginal bone reactions around osseointegrated implants: An animal experimental study. Clin. Oral Implants Res. 2001, doi:10.1034/j.1600-0501.2001.012003207.x.

68. Topkaya, T.; Solmaz, M.Y.; Dündar, S.; Eltas, A. Numerical analysis of the effect of implant geometry to stress distributions of the three different commercial dental implant system. Cumhur. Dent. J. 2015, 18, 17-24, doi:10.7126/cdj.58140.5000037693.

69. Cruz, M.; Wassall, T.; Toledo, E.M.; Barra, L.P. da S.; Lemonge, A.C. de C. Three-dimensional finite element stress analysis of a cuneiform-geometry implant. Int. J. Oral Maxillofac. Implants 2003, 18, 675-84.

70. Eraslan, O.; Inan, Ö. The effect of thread design on stress distribution in a solid screw implant: A 3D finite element analysis. Clin. Oral Investig. 2010, 14, 411-416, doi:10.1007/s00784-009-0305-1.

71. Kong, L.; Liu, B.; Li, D.; Song, Y.; Zhang, A.; Dang, F.; Qin, X.; Yang, J. Comparative study of 12 thread shapes of dental implant designs: a three-dimensional finite element analysis. ISSN UK World J. Model. Simul. 2006, 1, 746-7233.

Chun, H.J.; Cheong, S.Y.; Han, J.H.; Heo, S.J.; Chung, J.P.; Rhyu, I.C.; Choi, Y.C.; Baik, H.K.; Ku, Y.; Kim, M.H. Evaluation of design parameters of osseointegrated dental implants using finite element analysis. J. Oral Rehabil. 2002, 29, 565-574, doi:10.1046/j.1365-2842.2002.00891.x.

73. Gupta, S.; Goyal, P.; Jain, A.; Chopra, P. Effect of peri-implantitis associated horizontal bone loss on stress distribution around dental implants-A 3D finite element analysis. Mater. Today Proc. 2020, 28, 1503-1509, doi:10.1016/j.matpr.2020.04.831.

74. Kittur, N.; Oak, R.; Dekate, D.; Jadhav, S.; Dhatrak, P. Dental implant stability and its measurements to improve osseointegration at the bone-implant interface: A review. Mater. Today Proc. 2020, doi:10.1016/j.matpr.2020.08.243.

75 .

Rahmanivahid, P.; Heidari, M. Effect of design parameters of dental implant on stress distribution : a finite element analysis. 2020, doi:10.14419/ijet.v9i3.30520.

76. Chakraborty, A.; Datta, P.; Majumder, S.; Mondal, S.C.; Roychowdhury, A. Finite element and experimental analysis to select patient's bone condition specific porous dental implant, fabricated using additive manufacturing. Comput. Biol. Med. 2020, 124, 103839, doi:10.1016/j.compbiomed.2020.103839.

77. Alaqeely, R.; Babay, N.; AlQutub, M. Dental implant primary stability in different regions of the Jawbone: CBCT-based 3D finite element analysis. Saudi Dent. J. 2020, 32, 101-107, doi:10.1016/j.sdentj.2019.06.001.

78. Valera-Jiménez, J.F.; Burgueño-Barris, G.; Gómez-González, S.; López-López, J.; Valmaseda-Castellón, E.; Fernández-Aguado, E. Finite element analysis of narrow dental implants. Dent. Mater. 2020, 36, 927-935, doi:10.1016/j.dental.2020.04.013.

79. Nimbalkar, S.; Dhatrak, P.; Gherde, C.; Joshi, S. A review article on factors affecting bone loss in dental implants. Mater. Today Proc. 2020, doi:10.1016/j.matpr.2020.07.428.

80. Joshi, J.; Gariya, N.; Manral, A.R.; Kumar, P. Comparative analysis of a human tooth using different materials based on the finite element method. Mater. Today Proc. 2020, 2-6, doi:10.1016/j.matpr.2020.06.021.

81. Jeng, M.D.; Lin, Y.S.; Lin, C.L. Biomechanical evaluation of the effects of implant neckwall thickness and abutment screw size: A 3D nonlinear finite element analysis. Appl. Sci. 2020, 10, 10-16, doi:10.3390/app10103471.

82. Shetty, P.; Yadav, P.; Tahir, M.; Saini, V. Implant Design and Stress Distribution. Int. J. Oral Implantol. Clin. Res. 2016, 7, 3439, doi:10.5005/jp-journals-10012-1151.

83. Reilly, D.T.; Burstein, A.H. The elastic and ultimate properties of compact bone tissue. J. Biomech. 1975, 8, doi:10.1016/00219290(75)90075-5.

84. Xiao, J.R.; Li, Y.F.; Guan, S.M.; Song, L.; Xu, L.X.; Kong, L. The biomechanical analysis of simulating implants in function under osteoporotic jawbone by comparing cylindrical, apical tapered, neck tapered, and expandable type implants: A 3dimensional finite element analysis. J. Oral Maxillofac. Surg. 2011, 69, 273-281, doi:10.1016/j.joms.2010.12.006. 
